\title{
Retrieval and intercomparison of volcanic SO2 injection height and eruption time from satellite maps and ground- based observations
}

DOI:

10.1016/j.jvolgeores.2016.12.008

\section{Document Version}

Accepted author manuscript

Link to publication record in Manchester Research Explorer

Citation for published version (APA):

Pardini, F., Burton, M., de' Michieli Vitturi, M., Corradini, S., Salerno, G., Merucci, L., \& Di Grazia, G. (2016).

Retrieval and intercomparison of volcanic SO2 injection height and eruption time from satellite maps and groundbased observations. Journal of Volcanology and Geothermal Research.

https://doi.org/10.1016/j.jvolgeores.2016.12.008

Published in:

Journal of Volcanology and Geothermal Research

\section{Citing this paper}

Please note that where the full-text provided on Manchester Research Explorer is the Author Accepted Manuscript or Proof version this may differ from the final Published version. If citing, it is advised that you check and use the publisher's definitive version.

\section{General rights}

Copyright and moral rights for the publications made accessible in the Research Explorer are retained by the authors and/or other copyright owners and it is a condition of accessing publications that users recognise and abide by the legal requirements associated with these rights.

\section{Takedown policy}

If you believe that this document breaches copyright please refer to the University of Manchester's Takedown Procedures [http://man.ac.uk/04Y6Bo] or contact uml.scholarlycommunications@manchester.ac.uk providing relevant details, so we can investigate your claim.

\section{OPEN ACCESS}




\section{Accepted Manuscript}

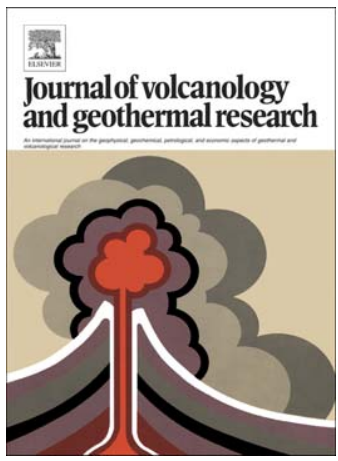

Retrieval and intercomparison of volcanic $\mathrm{SO}_{2}$ injection height and eruption time from satellite maps and ground-based observations

Federica Pardini, Mike Burton, Mattia de' Michieli Vitturi, Stefano Corradini, Giuseppe Salerno, Luca Merucci, Giuseppe Di Grazia

PII:

S0377-0273(16)30244-X

DOI:

doi: 10.1016/j.jvolgeores.2016.12.008

Reference:

VOLGEO 5979

To appear in: Journal of Volcanology and Geothermal Research

Received date: 5 August 2016

Revised date: 22 December 2016

Accepted date: $\quad 24$ December 2016

Please cite this article as: Pardini, Federica, Burton, Mike, de' Michieli Vitturi, Mattia, Corradini, Stefano, Salerno, Giuseppe, Merucci, Luca, Di Grazia, Giuseppe, Retrieval and intercomparison of volcanic $\mathrm{SO}_{2}$ injection height and eruption time from satellite maps and ground-based observations, Journal of Volcanology and Geothermal Research (2016), doi:10.1016/j.jvolgeores.2016.12.008

This is a PDF file of an unedited manuscript that has been accepted for publication. As a service to our customers we are providing this early version of the manuscript. The manuscript will undergo copyediting, typesetting, and review of the resulting proof before it is published in its final form. Please note that during the production process errors may be discovered which could affect the content, and all legal disclaimers that apply to the journal pertain. 
Retrieval and intercomparison of volcanic $\mathrm{SO}_{2}$ injection height and eruption time from satellite maps and ground-based observations

Federica Pardini ${ }^{1}$, Mike Burton ${ }^{1}$, Mattia de' Michieli Vitturi ${ }^{2}$, Stefano Corradini ${ }^{3}$, Giuseppe Salerno ${ }^{4}$, Luca Merucci $^{3}$, Giuseppe Di Grazia ${ }^{4}$.

${ }^{1}$ School of Earth and Environmental Science, University of Manchester, UK.

${ }^{2}$ Istituto Nazionale di Geofisica e Vulcanologia - Sezione di Pisa, Italy.

${ }^{3}$ Istituto Nazionale di Geofisica e Vulcanologia - Sezione di Roma, Italy.

${ }^{4}$ Istituto Nazionale di Geofisica e Vulcanologia - Sezione di Catania Osservatorio Etneo, Italy.

Keywords: volcanic SO2, trajectory modelling, remote sensing, volcanic tremor. 


\section{Abstract}

Syneruptive gas flux time series can, in principle, be retrieved from satellite maps of $\mathrm{SO}_{2}$ collected during and immediately after volcanic eruptions, and used to gain insights into the volcanic processes which drive the volcanic activity. Determination of the age and height of volcanic plumes are key prerequisites for such calculations. However, these parameters are challenging to constrain using satellite-based techniques. Here, we use imagery from OMI and GOME-2 satellite sensors and a novel numerical procedure based on backtrajectory analysis to calculate plume height as a function of position at the satellite measurement time together with plume injection height and time at a volcanic vent location. We applied this new procedure to three Etna eruptions (12 August 2011, 18 March 2012 and 12 April 2013) and compared our results with independent satellite and ground-based estimations. We also compare our injection height time-series with measurements of volcanic tremor, which reflects the eruption intensity, showing a good match between these two datasets. Our results are a milestone in progressing towards reliable determination of gas flux data from satellite-derived $\mathrm{SO}_{2}$ maps during volcanic eruptions, which would be of great value for operational management of explosive eruptions. 


\section{Introduction}

Sulphur dioxide $\left(\mathrm{SO}_{2}\right)$ is normally the most abundant gas released into the atmosphere by volcanic eruptions after water vapour $\left(\mathrm{H}_{2} \mathrm{O}\right)$ and carbon dioxide $\left(\mathrm{CO}_{2}\right)$ (Sigurdsson et al., 2015). While $\mathrm{H}_{2} \mathrm{O}$ and $\mathrm{CO}_{2}$ are abundant in Earth's atmosphere, $\mathrm{SO}_{2}$ is not, making volcanic $\mathrm{SO}_{2}$ easier to detect from satellite- and ground-based instruments.

Part of the interest in $\mathrm{SO}_{2}$ detection derives from the potential for reconstructing $\mathrm{SO}_{2}$ fluxes and plume height time-series, which could, in principle, produce deeper insights into the volcanic processes which drive eruptions. For example, Young et al., (1988) and Williams-Jones et al., (2008) show that $\mathrm{SO}_{2}$ fluxes measured at active volcanoes are a good proxy for magma supply rate. Moreover, $\mathrm{SO}_{2}$ injected at stratospheric heights from large eruptions can play a role in climate due to $\mathrm{SO}_{2}$ conversion into a sulphate aerosol. Such particles can remain in the upper atmosphere for weeks or even months offering a screen to solar radiation and causing global cooling (Bluth et al., 1992; Bekki, 1995; Carn et al., 2007; McCormick et al., 1995; Robock, 2000). Finally, $\mathrm{SO}_{2}$ plumes are often used as a proxy for ash clouds (Sears et al., 2013; Carn et al., 2009; Thomas and Prata, 2011), motivating their detection for the purposes of aircraft hazard mitigation. Thus, an accurate quantification of $\mathrm{SO}_{2}$ flux time series from satellite imagery during volcanic eruptions would be of great value, but is not currently routinely performed, due to a lack of reliable and robust analysis procedures.

Remote measurements of $\mathrm{SO}_{2}$ amount released by volcanic activity can be achieved both by ground- and satellite-based sensors. In the first case, $\mathrm{SO}_{2}$ emission rates are typically measured using systems such as ultraviolet spectrometers (Galle et al., 2003; Salerno et al., 2009) or high resolution cameras (Mori and Burton 2006; Nadeau et al., 2011, Burton et al., 2015) located around active volcanoes. However, the vast majority of volcanoes on 
Earth are not intensely monitored from the ground, and even for those that are, strongly explosive eruptions pose a challenge for proximal ground-based $\mathrm{SO}_{2}$ fluxes networks. Satellite-based $\mathrm{SO}_{2}$ detection offers a solution to fill this gap, if reconstruction of $\mathrm{SO}_{2}$ emission rate time series can be produced robustly (Merucci et al., 2011).

Volcanic $\mathrm{SO}_{2}$ can be detected by Ultraviolet (UV) and Infrared (IR) satellite sensors. Example instruments include ASTER (Advanced Spaceborne Thermal Emission and Reflection Radiometer) (Tan, 2004), AIRS (Atmospheric Infrared Sounder) (Chahine et al., 2006) and MODIS (Moderate Resolution Imaging Spectroradiometer) (Salomonson et al., 2002) aboard Nasa's Terra and Aqua satellites. We also cite SEVIRI (Spinning Enhanced Visible and InfraRed Imager) (Aminou, 2002) on Meteosat Second Generation spacecraft, OMI (Ozone Monitoring Instrument) on board NASA's Aura satellite (Levelt et al., 2006), GOME-2 (Global Ozone Monitoring Experiment-2) (Munro et al., 2006) and IASI (The Infrared Atmospheric Sounding Interferometer) (Blumstein et al., 2004) both aboard MetOp-A/B. More recent instruments are VIIRS (Visible Infrared Imaging Radiometer Suite) (Liao et al., 2013), OMPS (Ozone Mapping and Profile Suite) (Cao et al., 2013) and CrIS (Cross-track Infrared Sounder) (Strow et al., 2013) all aboard Suomi NPP satellite launch in 2011.

When retrieving volcanic $\mathrm{SO}_{2}$ abundance using satellite measurements, difficulties arise due to uncertainties in calculating the plume height at measurement point, which is an essential information for accurate retrievals of $\mathrm{SO}_{2}$ abundance and, consequently, fluxes (Pugnaghi et al., 2013; Theys et al., 2013). The most immediate information that can be extracted from a satellite image of an $\mathrm{SO}_{2}$ plume is its static position, at a fixed time, without knowledge about its height and its temporal evolution. Some satellite-based retrieval techniques have been developed allowing the simultaneous reconstruction of both column amounts and height of volcanic $\mathrm{SO}_{2}$ clouds. For example, Yang et 
al., (2010) presents the Extended Iterative Spectral Fitting (EISF) algorithm for retrieving plume altitude and column amount using observations of the 2008 Kasatochi eruption made by OMI. Clarisse et al., (2014) introduces and validates a new method for the retrieval of $\mathrm{SO}_{2}$ plume height from IASI measurements using the Nabro 2011 eruption as a case study. Hyperspectral infrared observations (Carboni et al., 2012, 2015) and inverse modelling procedures (Moxnes et al., 2014; Boichu et al., 2013, 2015) have also shown promising results.

We highlight that the accuracy of any satellite plume altitude retrieval is influenced by parameters such as $\mathrm{SO}_{2}$ column amount (retrievals work best for high total column), presence of volcanic ash or aerosol in the plume and pixels not completely covered by the plume.

In the present paper, we report a methodology for retrieving $\mathrm{SO}_{2}$ plume height and temporal evolution using a combination of satellite data and numerical modelling. Three Etna volcano paroxysmal events (eruptions occurred on 12 August 2011, 18 March 2012 and 12 April 2013) are investigated using observations made by OMI and GOME-2 satellite sensors. The methodology we present is fast and semi-automated and it can be easily performed with any type of satellite data, making our tool potentially suitable for operational tasks, such as use in VAACs or volcano observatories.

We compare our numerical products (i.e. injection time, injection height and cloud height at satellite measurement time) with independent ground- and satellite-based estimations of the same eruptive parameters. For this reason, Etna is a suitable target for our analysis since it is a very well-monitored volcano by both satellite- and ground-based systems. Here, satellite-derived injection times are compared with eruption times captured by visible imagery from ground-visible cameras located in Catania $27 \mathrm{~km}$ from the vent (Scollo et al., 2014). Our satellite $\mathrm{SO}_{2}$ image-derived injection heights are compared with 
those arising from the 'dark pixel' procedure (Prata and Grant, 2001; Corradini et al., 2010) applied to satellite SEVIRI data, and those from calibrated groundbased visible camera images (Scollo et al., 2014). Volcanic cloud heights at satellite measurement time are examined together with the results of the centre of mass procedure applied to SEVIRI measurements (Guerrieri et al., 2015).

The outcomes of the numerical procedure are also compared with volcanic seismic tremor signals recorded at Etna during the investigated eruptions. Volcanic tremor has been recognized as a proxy for eruption intensity (Alparone et al., 2003). Comparing our injection height time-series with tremor signal, we find a good match between these two datasets even if deeper analysis is needed to better explain this behaviour.

The paper is structured as follows. The three Etna cases study are described in Section 2, while an overview of the satellite data used to perform the numerical procedure is presented in Section 3. Section 4 shows the methodology and the outcomes for the three investigated eruptions. The comparison between numerical results and independent satellite- and ground-based estimations is presented in Section 5. Finally, in Section 6 we compare our numerically retrieved injection height times-series with volcanic tremor signal recorded during the investigated eruptions and we show a good match between these independent datasets. 


\section{Etna case study}

Etna $\left(37.73^{\circ} \mathrm{N}, 15.00^{\circ} \mathrm{E}\right)$ is a stratovolcano located on the Eastern coast of Sicily, Italy with an elevation of 3300 m ASL 4 active summit craters: Voragine (VOR), North-east (NEC), Bocca Nuova (BN), New-South-East (NSEC) (see Figure 1).

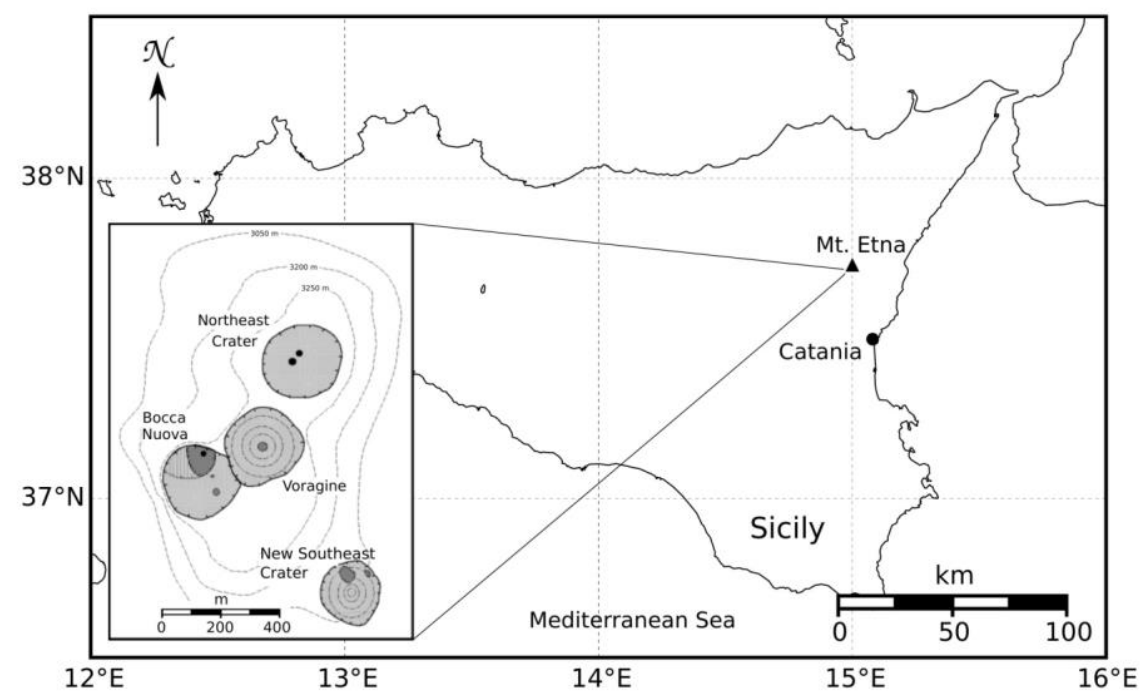

Figure 1: Sketch map of Sicily, Italy, where Mt. Etna (3300 m asl) is located $\left[37.73^{\circ}, 15.00^{\circ}\right]$. The morphology of the four summit craters (Voragine, Northeast, Bocca Nuova, New-South-East) during 2011-2013 is shown in the inset.

Etna is the tallest volcano in Europe and one of the most active volcanoes in the world. Geophysical, geochemical and volcanic signals produced by volcanic activity and unrest are continuously measured with extensive, modern monitoring networks managed by INGV-Osservatorio Etneo resulting in a large, high quality dataset which is extremely valuable for scientific research.

From January 2011 to December 2013 Etna produced a series of 44 paroxysmal eruptive episodes, with lava fountains reaching up to $1 \mathrm{~km}$ in height above the summit craters, together with the creation of sustained ash and gas columns reaching higher heights (Calvari et al., 2011; Patanè et al., 2013). This activity 
had its source from a new vent that opened on the southeast flank of the SEC. Due to the accumulation of pyroclastic material during the period 2011-2012, this depression produced a new cone with a total elevation of more than 200 meters, the so called New Southeast Crater (NSEC) (Behncke et al., 2014).

Three paroxysmal events of the 2011-2013 eruptive episodes fed by NSEC are used as test cases in the present paper. These are the eruptions which occurred on 12 August 2011, 18 March 2012 and 12 April 2013. These eruptions have been selected considering the availability of satellite- and ground-based data used to perform our analysis. Below we report brief descriptions of the case studies, with information about the eruptive activity arising from INGV Osservatorio Etneo reports available at www.ct.ingv.it.

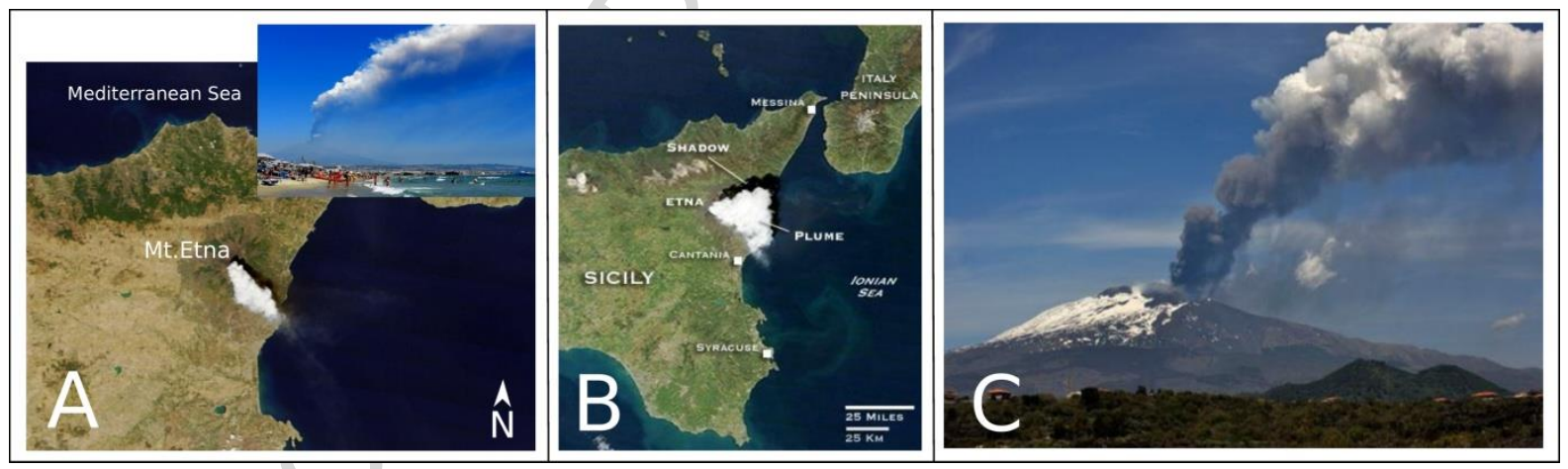

Figure 2: (A) MODIS satellite image showing the plume released during the 12 August 2011 Etna event (image courtesy NASA MODIS Rapid Response System); inset figure shows the eruptive column and the plume as seen from Catania at $30 \mathrm{~km}$ distance from the top of Etna (image courtesy Elisabetta Ferrera, University of Catania); (B) MODIS satellite image of the plume released during the 18 March 2012 eruption (image courtesy NASA MODIS Rapid Response System); (C) eruptive column and plume emitted during the 12 April 2013 event (image courtesy Roberto Caudullo, https://etnavolcano.wordpress.com). 


\subsection{August 2011}

The 12 August 2011 event was the $10^{\text {th }}$ paroxysm of 2011 and it took place after a relatively quiet six day pause in activity (see Figure 2A).

At about 5.30 UTC (all timings reported here are UTC) on 12 August an intense phase of Strombolian activity was observed, with an amplification of volcanic tremor amplitude recorded by the seismic network and a contemporaneous migration of tremor source from the central summit area towards the NSEC. Dark ash puffs began at 7:30 followed by a lava flow at 7:50 in the direction of Valle del Bove. The paroxysmal phase started at 8:00 when violent Strombolian explosions were converted into pulsating fountains $\sim 100 \mathrm{~m}$ tall. Between 8:45 and 10:00 a dense ash column rose from the lava fountain. Ash and lava emissions continued until 10:25 when a decrease in the intensity was observed and only a phase of passive ash emission remained. The eruption ended at 11:00 on 12 August.

\subsection{March 2012}

The paroxysmal episode that occurred on 18 March 2012 was the $22^{\text {nd }}$ event of the 2011-2013 eruptive cycle (see Figure 2B).

From early morning on 18 March 2012, monitoring signals indicate unrest of Etna. Strombolian activity together with volcanic tremor amplitude became gradually more intense and after 6:00 lava started to overflow towards Valle del Bove. At 7:25 an ash and gas-rich plume rose from the crater, while pulsating lava fountains reached a height of $100 \mathrm{~m}$ above the vent. Between 8:00 and 8:15 the lava fountain activity was continuous and a several kilometres high eruptive column was observed at around 9:00 blown eastward by the wind. Lava fountains and strong ash emissions lasted until 9:40 without significant variations; after this the activity rapidly diminished in intensity to end at 10:10. 


\subsection{April 2013}

The $10^{\text {th }}$ eruptive event of 2013 occurred at the NSEC and, in contrast to the previously described episodes, this eruption lasted for several days (from 8 to 14 April 2013) reaching a peak on 12 April 2013 (see Figure 2C).

Strombolian explosions started on 8 April 2013 and weak ash emission with intermittent mild explosions went on until 11 April when a stronger activity was observed together with increasing volcanic tremor amplitude. At dawn on 12 April a diluted ash cloud rose from the NSEC and drifted southeast.

During the morning of 12 April 2013 the paroxysmal phase was characterized by lava flow, frequent, strong Strombolian explosions and a weak ash emission. At 10:00 the eruptive activity suddenly decreased in intensity and the lava fountains turn into sporadic Strombolian explosions with very weak ash emissions, while the amplitude of the volcanic tremor decreased. At 10:15 the activity increased again and new lava fountains together with strong ash emissions heralded the beginning of a new paroxysmal phase which remained stable until midday. The eruptive activity ceased at 15:00 on 12 April. This episode was significantly less intense than 12 August 2011 and 18 March 2012, but of longer duration.

\section{Satellite data}

$\mathrm{SO}_{2}$ spatial distributions of the investigated case studies arose from both OMI and GOME-2 operational products. OMI, on board NASA's Aura satellite, is a nadir-viewing imaging spectrometer in the spectral range of 264-504 nm performing a global and daily measurement of several atmospheric gases as $\mathrm{SO}_{2}, \mathrm{NO}_{2}, \mathrm{BrO}, \mathrm{HCHO}$, etc. Each orbit has a swath of $2600 \mathrm{~km}$ width, composed by 1600 line-viewing containing 60 pixels each with a ground pixel size at nadir of $13 \times 24 \mathrm{~km}^{2}$. Since May 2008 the so-called OMI Row Anomaly (ORA) degraded the quality of the Level $1 \mathrm{~B}$ radiance data and consequently the 
$\mathrm{SO}_{2}$ data products. A row anomaly is an anomaly affecting the Earth radiance data at all the wavelengths for specific OMI viewing angles. These anomalies appeared to be changing with time and affecting different viewing angle of OMI after their first appearance; however, they are stable since July 2011. Yan et al., (2012) shows a method for correcting $\mathrm{OMI} \mathrm{SO}_{2}$ Band Residual Difference (BRD) retrievals affected by rows anomalies. More information about the Row Anomalies be be bund at http://www.knmi.nl/omi/research/product/rowanomaly-background.php.

GOME-2 is an ultraviolet spectrometer $(290-790 \mathrm{~nm})$ aboard the polar-orbiting satellites MetOp-A (launched in 2006) and MetOp-B (launched in 2012) taking global measurements of atmospheric composition on a daily basis. GOME-2 provides nadir-view scans with a swath of $1920 \mathrm{~km}$ and a ground pixel resolution of 40x80 $\mathrm{km}^{2}$. Since plume height cannot be simply assessed by satellite measurements (hence necessitating methods such as those presented in the current work), for each OMI and GOME-2 scene the $\mathrm{SO}_{2}$ Column Amount (CA) is retrieved assuming four different hypothetical $\mathrm{SO}_{2}$ plume heights in case of OMI and three different heights in case of GOME-2 (Rix et al., 2012).

The a-priori altitudes used in the analysis of the OMI radiance are: Planetary Boundary Layer (PBL, $0.9 \mathrm{~km}$ ), Lower Troposphere (TRL, $2.5 \mathrm{~km})$, Middle Troposphere (TRM, $7.5 \mathrm{~km}$ ) and Upper Troposphere/Stratosphere (STL, 17 $\mathrm{km})$.

For each of these hypothetical heights, the CA is retrieved in Dobson Units [DU] using different Principal Component Analysis algorithm for $0.9 \mathrm{~km}$ ( $\mathrm{Li}$ et al., 2013) and Linear Fit algorithms for 2.5, 7.5 and $17 \mathrm{~km}$ heights (Yang et al., 2007).

Similarly, for each GOME-2 scene three different $\mathrm{SO}_{2} \mathrm{CA}$ maps are retrieved for heights equal to $2.5 \mathrm{~km}, 6 \mathrm{~km}$ and $15 \mathrm{~km}$. For each of these heights the 
retrieval of the $\mathrm{SO}_{2}$ atmospheric amount is made using the differential optical absorption spectroscopy (DOAS) method in the UV (Platt and Stutz, 2008).

Since we make no assumptions on the height at which the $\mathrm{SO}_{2}$ cloud is located at the satellite overpass, we use the TRL maps $(2.5 \mathrm{~km})$ for the test cases investigated with OMI and the map retrieved at $2.5 \mathrm{~km}$ for the test case investigated with GOME-2.

OMI's $0.9 \mathrm{~km}$ altitude retrievals are restricted to optimal viewing conditions and they are not recommended to be used for volcanological purposes (Carn et al., 2013). The CA values reported on $2.5 \mathrm{~km}$ and $7.5 \mathrm{~km}$ maps are wellcorrelated, especially in the case of a cloud-free atmosphere and just a changing in column magnitude can be observed between the two maps. In addition, the $2.5 \mathrm{~km}$ retrieval overestimates the column amount if the $\mathrm{SO}_{2}$ height is more than $3 \mathrm{~km}$ in height. For these reasons we use the $2.5 \mathrm{~km}$ map initially purely to localize the spatial distribution of the $\mathrm{SO}_{2}$ plume without taking into account its effective amount.

For the same reason, i.e. an overestimation of the $\mathrm{SO}_{2}$ loading at lower heights due to the necessity of simply localize the plume spatial distribution, we use the GOME-2 retrievals at $2.5 \mathrm{~km}$.

The Simple Subset Wizard (SSW) data store by NASA's Goddard Earth Sciences Data and Information Services Center (GES DISC) is the source of the OMI operational products, while the GOME-2 products are downloaded from the Support to Aviation Control Service (SACS) web page (Brenot et al., 2014).

\section{Numerical procedure}

There are two plume heights which are retrieved in our methodology. The first is the mean plume height where $\mathrm{SO}_{2}$ is detected at the moment of satellite image observation (hereafter named volcanic cloud height), whereas the second is the 
mean $\mathrm{SO}_{2}$ injection plume height above the volcanic vent position. This second height represents the height at which the atmospheric wind spreads the plume into the atmosphere at vent location. We also retrieve the time interval during which the injection of the $\mathrm{SO}_{2}$ plume takes place above a volcanic vent. We use a back-trajectory analysis to retrieve these quantities, where each trajectory connects each pixel of the satellite image where $\mathrm{SO}_{2}$ is detected back to the volcanic vent.

Back-trajectory analysis is a widely used technique in the study of transport paths of ash, aerosols and gases dispersed into the atmosphere from both natural and anthropogenic sources (Flesch et al, 1995; Cape et al., 2000; Kim et al., 2001; Lin, 2001; Freiman et al., 2003; Grousset et al., 2003; McBain et al., 2005; Song et al., 2008; Zhu et al., 2011). Back-trajectory analysis of volcanic plumes has been performed by Hughes, et al. (2012) and Sellitto, et al. (2015) with the aim of studying the transport paths of $\mathrm{SO}_{2}$ clouds produced from volcanic eruptions.

The HYSPLIT (Hybrid Single-Particle Lagrangian Integrated Trajectory) Model (Draxler et al., 2003) has been selected to perform back-trajectory calculations. HYSPLIT is an open-source code developed by NOAA's ARL (Air Resources Laboratory) which is able to calculate both air parcel trajectories and dispersion simulations. We developed Python scripts to run HYSPLIT routines in order to analyse satellite images of $\mathrm{SO}_{2}$ maps in a semi-automatic manner and calculate plume heights and injection time intervals. A detailed description of the methodology follows, with the example of analysis of the $\mathrm{SO}_{2}$ image captured on 12 August 2011.

\subsection{Back-trajectory simulation}

The $\mathrm{SO}_{2}$ plume emitted from Etna during the 12 August 2011 paroxysm event was measured by OMI, producing a $2.5 \mathrm{~km}$ map collected at 13:03 on 12 
August 2011 which shows a maximum $\mathrm{SO}_{2} \mathrm{CA}$ value of $28 \mathrm{DU}$ (see Figure 3A). As in Carn et al., (2008), an $\mathrm{SO}_{2}$ column threshold $\left(C A_{\text {lim }}\right)$ is assigned in order to isolate the volcanic $\mathrm{SO}_{2}$ signal from the background using the relationship:

$C A_{\text {lim }}=C A_{\text {mean }}+3 \sigma_{C A}$,

where $C A_{\text {mean }}$ is the mean column value computed in a free $\mathrm{SO}_{2}$ region $(0.13$ DU) and $\sigma_{C A}$ is the relative standard deviation (0.12 DU). In this way 25 pixels with a columnar abundance higher than 0.5 DU $\left(C A_{\text {lim }}\right)$ are selected, see Figure $3 \mathrm{~A}$.

The 65 degrees off-nadir position of the analysed satellite track section with respect to the satellite position leads to quite coarse pixels with sizes of $13 \mathrm{~km}$ in latitude and $110 \mathrm{~km}$ in longitude. Thus, there are two possibilities for the $\mathrm{SO}_{2}$ spatial location inside each pixel. The first one is that the gas actually occupies the total area of the pixel and, in this case, the pixel size reflects the actual shape of the plume. The second possibility is that the $\mathrm{SO}_{2}$ does not occupy the entire pixel, but it covers just a part of it. In order to retrieve the spatial position of the plume despite pixels coarse resolution, we map the original OMI data on a refined grid composed of sub-pixels with size $4.5 \mathrm{~km}$ in latitude and $11 \mathrm{~km}$ in longitude one, as shown in Figure 3B. 

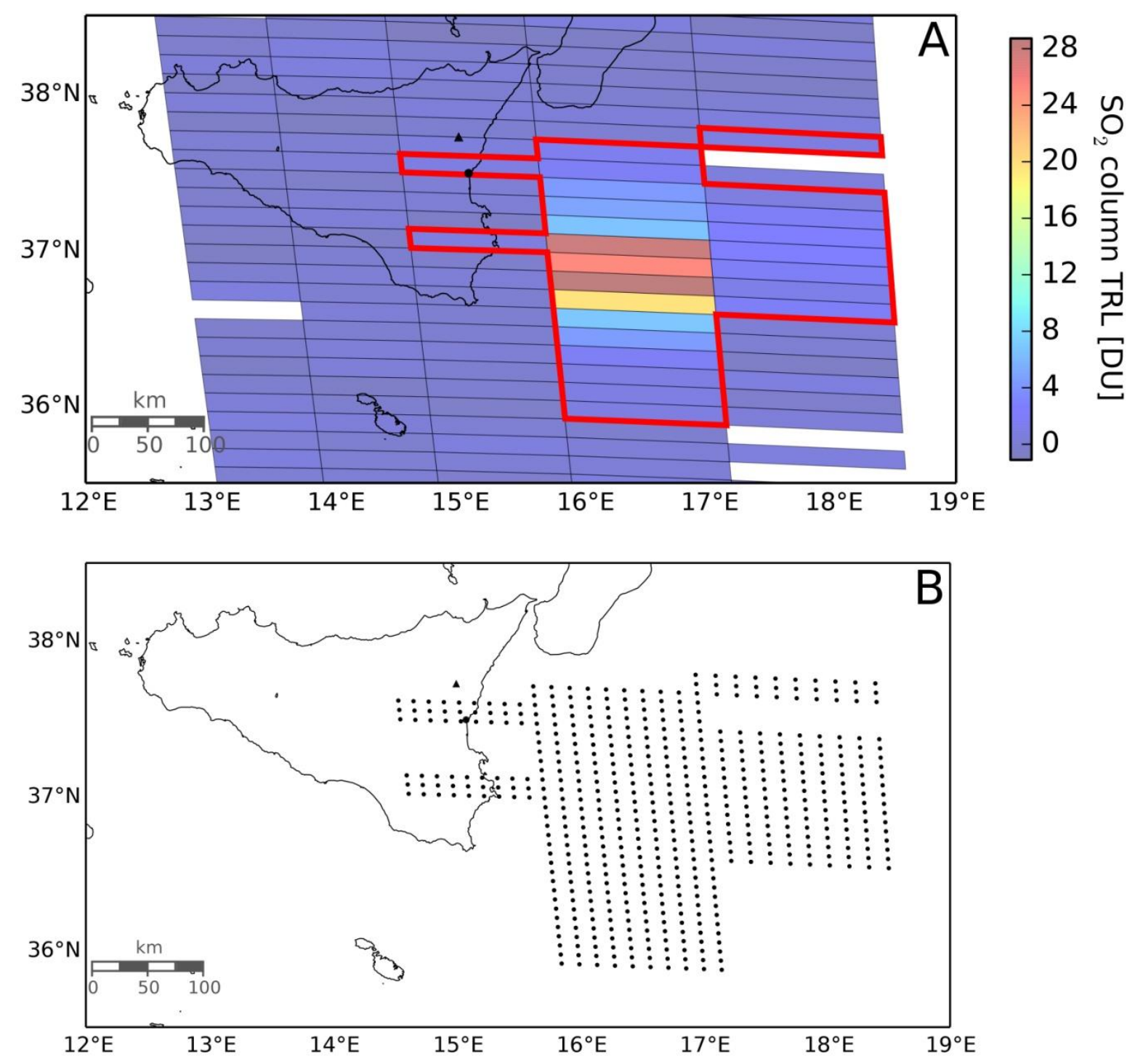

Figure 3: (A) $\mathrm{SO}_{2}$ plume emitted during the 12 August 2011 eruption observed by OMI at 13:03 UTC on the same day; the red line highlights the pixels with a significant $\mathrm{SO}_{2}$ abundance used in the retrieval procedure; (B) Higher resolution grid used for the back-trajectory model. Selected pixels have been divided into sub-pixels of $11 \mathrm{~km}$ longitude and $4.5 \mathrm{~km}$ latitude. The centre position of each sub-pixel is shown as black dots on the figure.

This finer grid is chosen to reflect the maximum information available from the meteorological wind field data, which comes from the AMI (Aeronautica Militare Italiana) database. It is reported on a grid size of $6.67 \mathrm{~km}$ in latitude 
and longitude, updated every three hours, and with 13 pressure levels, from $1000 \mathrm{hPa}$ (pressure at sea level) to $10 \mathrm{hPa}$ (pressure at about $16500 \mathrm{~m} \mathrm{ASL}$ ). Using the 25 extracted pixels mapped onto the high resolution grid, a total of 528 sub-pixels are created and the lat-long centre position of each sub-pixel is then used as the starting coordinates on the horizontal plane for the backward trajectories. Twenty heights uniformly distributed every $500 \mathrm{~m}$ from $3000 \mathrm{~m}$ to $12000 \mathrm{~m}$ are chosen in the vertical coordinate (all the altitudes are referred to the sea level). Thus, a total number of 10560 starting points for the backtrajectories are initialized. We then perform a 'brute-force' approach, where every possible trajectory is calculated, and the best solutions in terms of coincidence with the horizontal position of the volcanic vent are selected by defining a threshold distance of approach to Etna vent location $\left[37.73^{\circ} \mathrm{N}\right.$, $15.00^{\circ} \mathrm{E}$ ] equal to $20 \mathrm{~km}$ (this choice is justified later in the text).

Spatial resolution uncertainties arising from performing the back-trajectory calculation on a finite grid can be evaluated running the backward trajectory calculation in the ensemble mode provided by HYSPLIT. This means that the wind field grid is moved slightly in the horizontal and vertical direction with respect to the original coordinates at which the trajectory is initialized. This offset allows the creation of a total number of 27 runs for each starting point. In this way the differences in the endpoints of the resulting trajectories give an estimate of the uncertainties due to divergence in the flow field. Offsets of $2 \mathrm{~km}$ and $5 \mathrm{~km}$ on the horizontal plane are selected (the offset remains smaller than the cell size), whereas an offset of $100 \mathrm{~m}$ is chosen on the vertical plane. Thus, from each starting point 27 trajectories are initialized resulting in a total number of 285120 trajectories, running back for 12 hours from the moment of data collection (12 August 2011 at 13:03).

Due to the high computational efficiency of the HYSPLIT model all these trajectories are calculated in only 30 minutes using a standard desktop PC. 


\subsection{Retrieval of plume heights and injection time}

Performing the back-trajectory simulation, we calculate a total of 285120 trajectories starting from the pixels of the image where $\mathrm{SO}_{2}$ is detected and ending somewhere in the domain.

The first step of the retrieval procedure is selecting those trajectories that, starting from a sub-pixel containing $\mathrm{SO}_{2}$, passes close to the horizontal position of Etna's summit. The selection of the subset of trajectories is done by defining a threshold distance of $20 \mathrm{~km}$ from Etna's summit $\left[37.73^{\circ} \mathrm{N}, 15.00^{\circ} \mathrm{E}\right]$. The trajectories that fail this test are rejected and we do not consider them in the following discussion. The choice of the threshold distance is consistent with the maximum plume width above the vent evaluated using visible images of the volcanic cloud (see Figure 2A). This generous threshold is also justified by considering that we are retrieving the heights at which the plume has been injected into the atmosphere after it has already been somewhat advected by the wind. Moreover, the eruptive column can be bent by the prevailing wind and the umbrella region can be transported far from the vent location. Thus, the physical interpretation of the parameters we are investigating requires a generous threshold distance-from-vent in order to be sure to capture the entire plume dynamics.

The approach we use in retrieving plume parameters is based on the idea that the finer grid used in the model allows us to presume a certain level of spatial and temporal homogeneity at least among the results coming from adjacent subpixels. Thus, we developed a post-processing routine which retrieves the plume parameters for each sub-pixel, $i$, of the grid considering the influence of the results coming from the adjacent ones.

Considering the $\mathrm{SO}_{2}$ contained in each sub-pixel $i$, we derive a mean injection time and height at vent position, $T_{\text {vent }}$ and $H_{\text {vent }}$ respectively, together with a 
mean volcanic cloud height $H$. The standard deviations are also computed and indicated as $\sigma_{T_{\text {vent }}}, \sigma_{H_{\text {vent }}}, \sigma_{\mathrm{H}}$.

To do this we indicate a generic trajectory as $\operatorname{traj}_{i k l}$, where $i=1,2, \ldots, n$ represents $i$-ith sub-pixel ( $n$ is the total number of sub-pixels), $k=$ $3000,3500, \ldots, 12000$ the height in meters from which the trajectory is initialized and $l=1,2, \ldots, 27$ accounts for the 27 trajectories resulting from the ensemble mode.

A weight coefficient $w_{i k l}$ is calculated for $t r a j_{i k l}$ in order to quantify its spatial and temporal correlation with the surrounding trajectories.

The procedure used in the calculation of $w_{i k l}$ is shown in Figure 4.

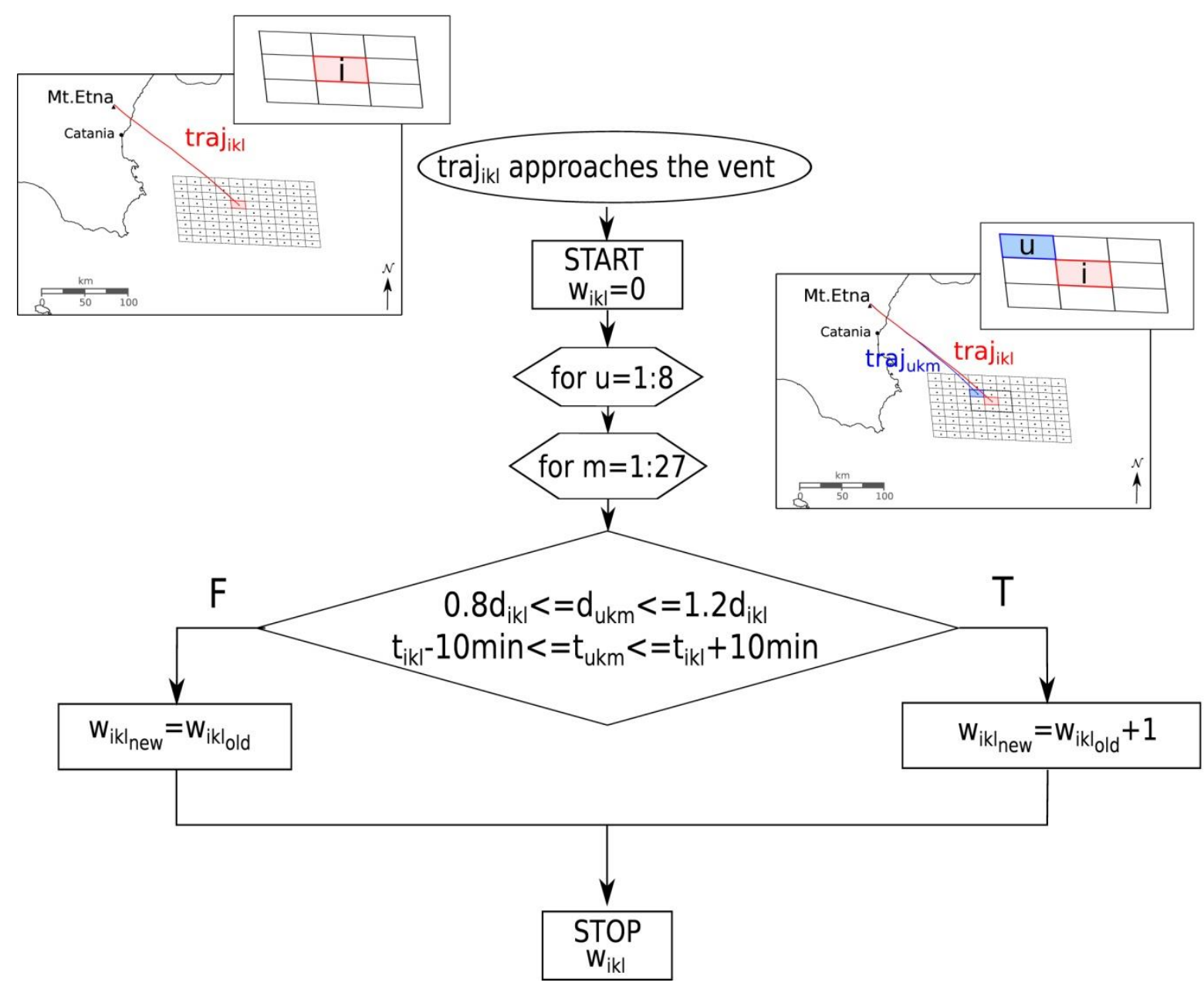


Figure 4: Retrieval scheme flow chart used for the calculation of the weight coefficient. For each $t r a j_{i k l}$ a weight coefficient $w_{i k l}$ is computed comparing the time instant and distance of approach to vent position between $\operatorname{traj}_{i k l}$ and trajectories $t r a j_{u k m}$ initialized near the investigated one.

The flowchart of Figure 4 starts with a null value for $w_{i k l}$; we then perform a loop over the 8 sub-pixels $u(u=1, \ldots, 8)$ bordering $i$ and for each of them a second loop over the 27 trajectories $m(m=1, \ldots, 27)$ starting from $u$ at the height $k$. Thus a trajectory $t r a j_{u k m}$ is selected during each iteration. We use the time and the distance of approach to vent position of $t r a j_{i k l}$ and $t r a j_{u k m}$ and we compare them using the following relationship:

$$
\begin{aligned}
& t_{i k l}-10 \text { min } \leq t_{u k m} \leq t_{i k l}+10 \text { min, } \\
& 0.8 \mathrm{~d}_{\mathrm{ikl}} \leq \mathrm{d}_{\mathrm{ukm}} \leq 1.2 \mathrm{~d}_{\mathrm{ikl}},
\end{aligned}
$$

where $t_{i k l}$ and $t_{u k m}$ are the times of approach to vent position expressed in HH:MM of $t r a j_{i k l}$ and $t r a j_{u k m}$ respectively, while $d_{i k l}$ and $d_{u k m}$ are the distances of approach in $\mathrm{km}$.

In this way we compare the moments in time $\left(t_{i k l}\right.$ and $\left.t_{u k m}\right)$ at which $t r a j_{i k l}$ and $t r a j_{u k m}$ pass near the volcanic vent and we examine if $t_{u k m}$ is within the temporal range specified in Eq. (2). We also consider the distances $\left(d_{i k l}\right.$ and $\left.d_{u k m}\right)$ at which $t r a j_{i k l}$ and $t r a j_{u k m}$ approach the vent, imposing a maximum difference of $20 \%$ (chosen by inspection) between them, Eq. (3).

If the conditions defined by Eq. (2) and Eq. (3) are verified, a +1 is added to $w_{i k l_{\text {new }}}$ otherwise it remains with the value computed during the previous iteration $\left(w_{i k l_{o l d}}\right)$. Once all iterations are completed, a final weight $w_{i k l}$ is computed for $\operatorname{traj}_{i k l}$. 
Repeating the procedure of Figure 4 for all the trajectories initialized from subpixel $i$, i.e. varying $l$ and $k$ in their ranges, a weight coefficient is computed for each of $t r a j_{i k l}$.

Thus, the mean injection time $\left(T_{\text {vent }}\right)$ and height $\left(H_{\text {vent }}\right)$ for the $\mathrm{SO}_{2}$ contained in sub-pixel $i$ are computed as:

$$
\begin{aligned}
& T_{\text {vent }}=\frac{\sum_{k, l}\left(t_{i k l_{\text {vent }}} * w_{i k l}\right)}{\sum_{k, l}\left(w_{i k l}\right)}, \\
& H_{\text {vent }}=\frac{\sum_{\mathrm{k}, \mathrm{l}}\left(\mathrm{h}_{i k l_{\text {vent }}} * \mathrm{w}_{\mathrm{ikl}}\right)}{\sum_{\mathrm{k}, \mathrm{l}}\left(\mathrm{w}_{\mathrm{ikl}}\right)},
\end{aligned}
$$

with $k$ varying every $500 \mathrm{~m}$ from $3000 \mathrm{~m}$ to $12000 \mathrm{~m}$ and $l$ ranging from 1 to

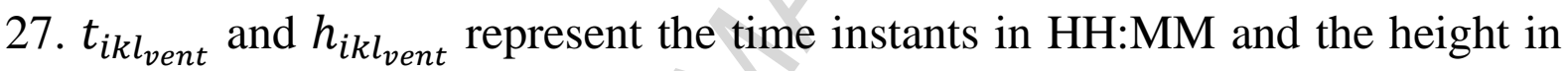
meters and at which $t r a j_{i k l}$ pass above the volcanic vent position respectively, and $w_{i k l}$ is the weighting coefficient previously evaluated.

In the same way, the mean volcanic cloud height $(H)$ for sub-pixel $i$ can be evaluated as:

$$
H=\frac{\sum_{k, l}\left(h_{i k l}{ }^{*} w_{i k l}\right)}{\sum_{k, l}\left(w_{i k l}\right)},
$$

where $h_{i k l}$ represents the height in meters at which each trajectory trajikl is initialized.

Similarly, weighted standard deviations $\left(\sigma_{T_{\text {vent }}}, \sigma_{H_{\text {vent }}}, \sigma_{H}\right)$ are evaluated using the equations:

$$
\begin{aligned}
& \sigma_{T_{\text {vent }}}=\sqrt[2]{\frac{\sum_{k, l} w_{i k l}\left(t_{i k l_{v e n t}}-T_{\text {vent }}\right)^{2}}{\sum_{k, l} w_{i k l}}}, \\
& \sigma_{H_{\text {vent }}}=\sqrt[2]{\frac{\sum_{k, l} w_{i k l}\left(h_{i k l_{\text {vent }}}-H_{\text {vent }}\right)^{2}}{\sum_{k, l} w_{i k l}}}, \\
& \sigma_{H}=\sqrt[2]{\frac{\sum_{k, l} w_{i k l}\left(h_{i k l}-H\right)^{2}}{\sum_{k, l} w_{i k l}}} .
\end{aligned}
$$


Thus, for each sub-pixel $i$ of the grid, three plume parameters are evaluated as mean weighted values and the uncertainties are taken into account by computing weighted standard deviations. The results are shown in the next section.

\subsection{Results of the 12 August 2011 eruption}

The results of the back-trajectory simulation of the 12 August 2011 event are shown in Figure 5.
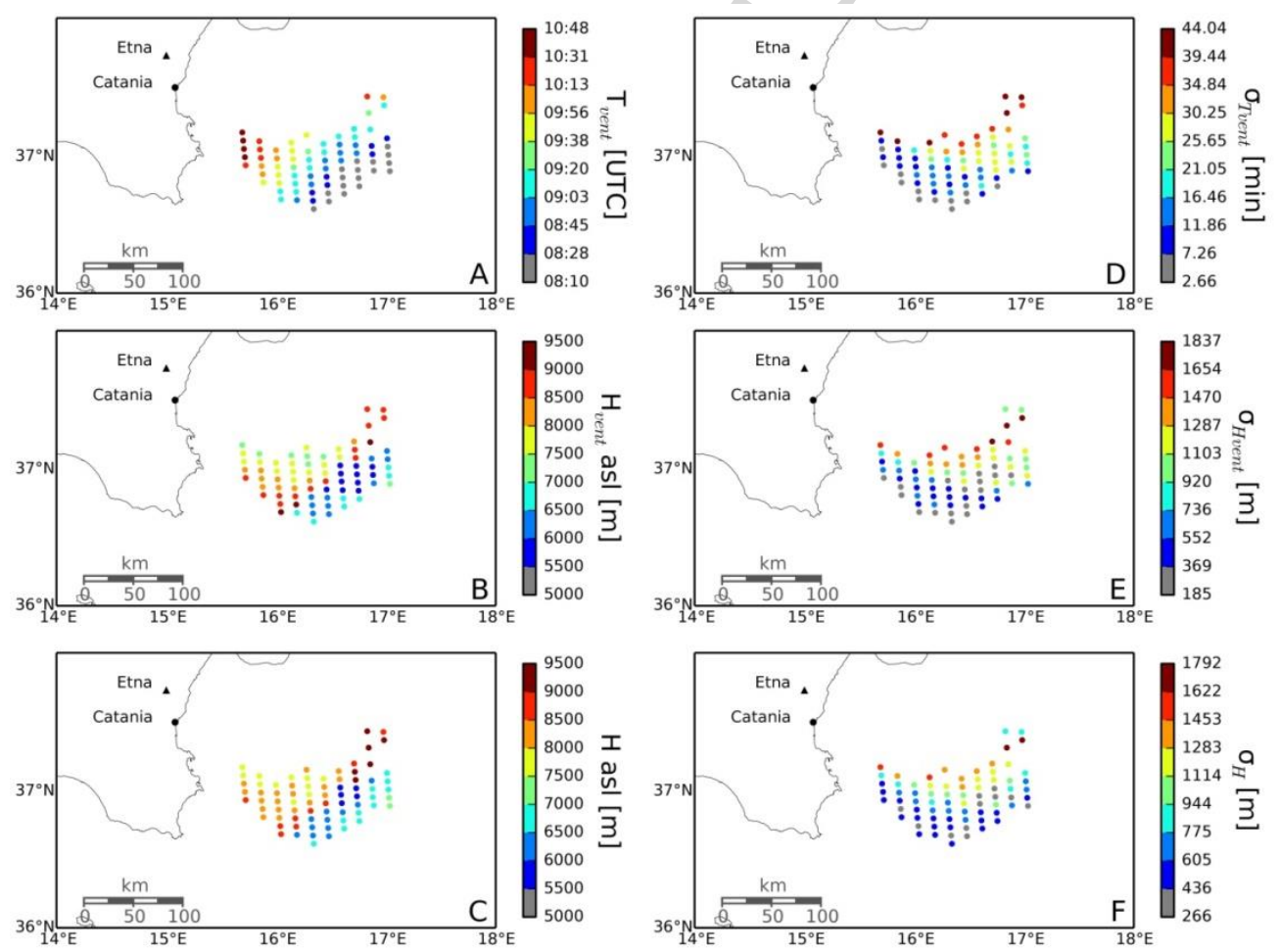

Figure 5: left panels (A-B-C) show the mean parameters $\left(T_{\text {vent }}, H_{\text {vent }}\right.$ and $H$ ) retrieved for the 12 August 2011 eruption. On the right (D-E-F) the standard deviations are reported $\left(\sigma_{T_{\text {vent }}}, \sigma_{H_{\text {vent }}}\right.$ and $\left.\sigma_{H}\right)$.

Figures $5 \mathrm{~A}-\mathrm{B}$ show the injection time $\left(T_{\text {vent }}\right)$ and height $\left(H_{\text {vent }}\right)$ above Etna, while the volcanic cloud height $(H)$ is reported in Figure 5C. Not all the initial sub-pixels produce back-trajectories that approach the vent, because only the sub-pixels presenting a standard deviation $\left(\sigma_{H}\right)$ less than or equal to $20 \%$ of the 
mean value $(H)$ are shown. This is done to better constrain the plume height, rejecting sub-pixels with less robust results. We note that sub-pixels which produce good quality results arise from pixels with the highest $\mathrm{SO}_{2}$ abundance. The off-nadir position of the OMI image leads to quite low resolution pixels which may capture only a fraction of the plume. In these cases, just a few subpixels reflecting the actual spatial distribution of the plume pass the selection criteria for starting points of back trajectories approaching the vent. We can therefore constrain the height and the time interval during which the bulk of the $\mathrm{SO}_{2}$ has been injected into the atmosphere.

What emerges is a continuous $\mathrm{SO}_{2}$ injection between 8:10 and 10:50 in the morning of 12 August with heights varying from $5500 \mathrm{~m}$ to $9500 \mathrm{~m}$. This trend is observed also for the volcanic cloud height, with a quite clear separation of the plume into two parts. That emitted between 8:10 and 8:45 is located at a lower height $(5500-7500 \mathrm{~m})$ compared with the latter which is located up to $9500 \mathrm{~m}$. Injection time standard deviations show a maximum uncertainty on the injection time $\left(\sigma_{\mathrm{T}_{\mathrm{vent}}}\right)$ of 44 minutes for a few sub-pixels located in the north part of the plume, while standard deviations from 3 to 20 minutes characterizes the majority of sub-pixels. Sub-pixels with the highest $\sigma_{\mathrm{T}_{\mathrm{vent}}}$ are those presenting the highest $\sigma_{\mathrm{H}_{\mathrm{vent}}}$ and $\sigma_{H}(1800 \mathrm{~m})$ as well, while an average uncertainty of $500 \mathrm{~m}$ characterizes the whole plume.

\subsection{Trajectory analysis and results: the 18 March 2012 eruption}

The second test case is the 18 March 2012 Etna eruption, whose $\mathrm{SO}_{2}$ plume was captured by OMI at 12:45 on the same day, as shown in Figure 6A. In this case the $\mathrm{OMI}$ image is missing some $\mathrm{SO}_{2}$ column information in fraction of pixels due to the 'OMI row anomaly' which caused a quality loss in the OMI radiance signal and cut off part of the image. However, the comparison of the OMI image with the one collected by AIRS at 12:40 on the same day shows that more than $50 \%$ of the plume is captured by OMI, and our study is focused on 
these pixels. Using the relationship of Eq. (1), 27 pixels showing a CA higher than $C A_{\text {lim }}=0.5 \mathrm{DU}$ are selected (see Figure 6A) and a high resolution grid is defined with cells of $10 \mathrm{~km}$ in longitude and $5 \mathrm{~km}$ in latitude, as reported in Figure 6B.
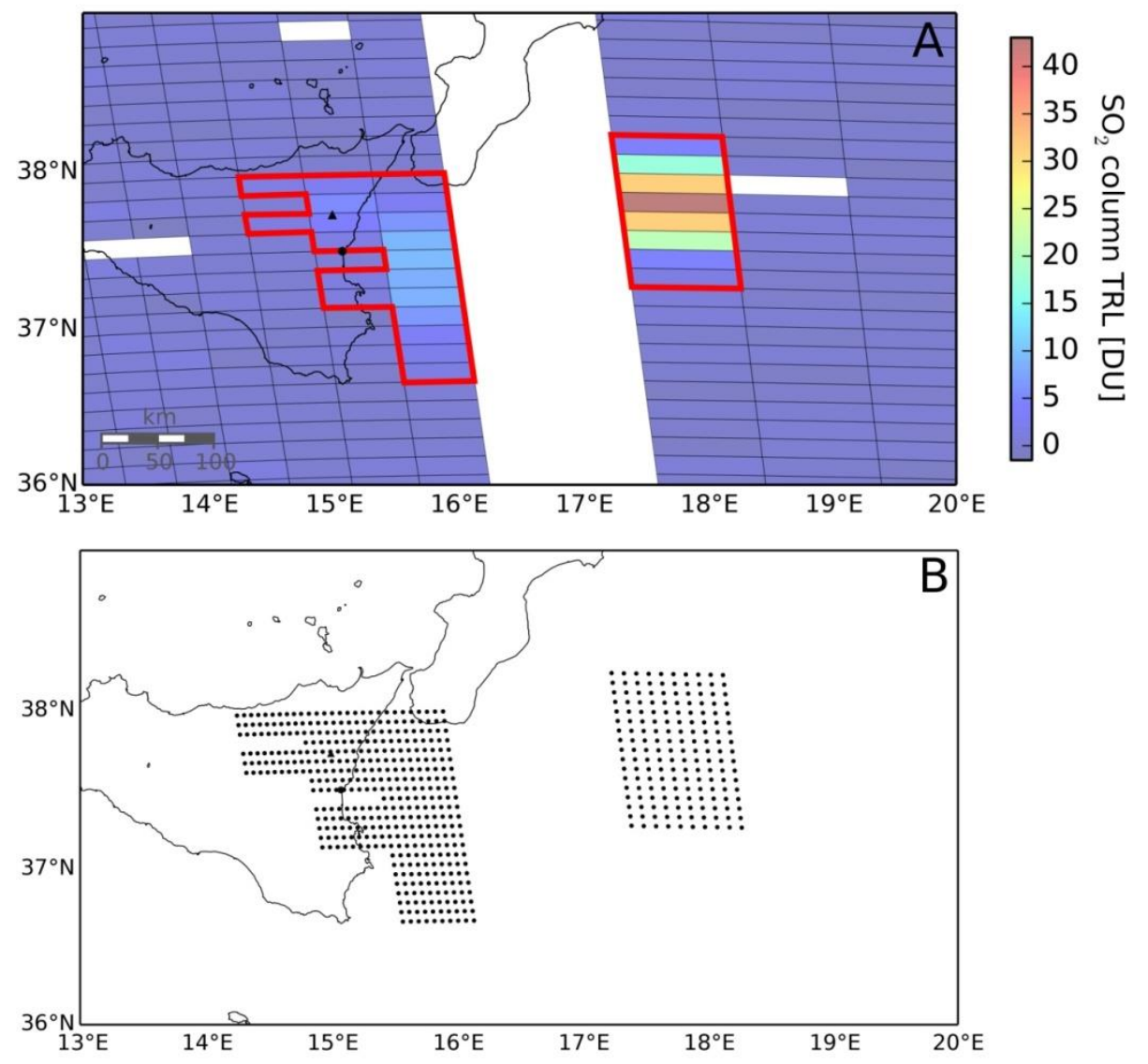

Figure 6: (A) OMI image collected at 12:45 UTC on 18 March 2012 showing the $\mathrm{SO}_{2}$ abundance in the atmosphere after the eruption; pixels with a columnar abundance greater than the background have been selected; (B) high resolution grid used in trajectory modelling.

A total of 20300 back-trajectories are calculated in a range of heights varying from $3000 \mathrm{~m}$ to $20000 \mathrm{~m}$ at intervals of $500 \mathrm{~m}$. Running HYSPLIT in ensemble mode, we produce a total number of 548100 back-trajectories initialized at the 
time instant of satellite measurement (18 March 2012 at 12:45) and running back in time for 12 hours.

Mean plume parameters $\left(T_{\text {vent }}, H_{\text {vent }}, H\right)$ and standard deviations $\left(\sigma_{T_{\text {vent }}}\right.$, $\left.\sigma_{H_{v e n t}}, \sigma_{H}\right)$ are computed for each sub-pixel following the procedure previously described and the results are shown in Figure 7.
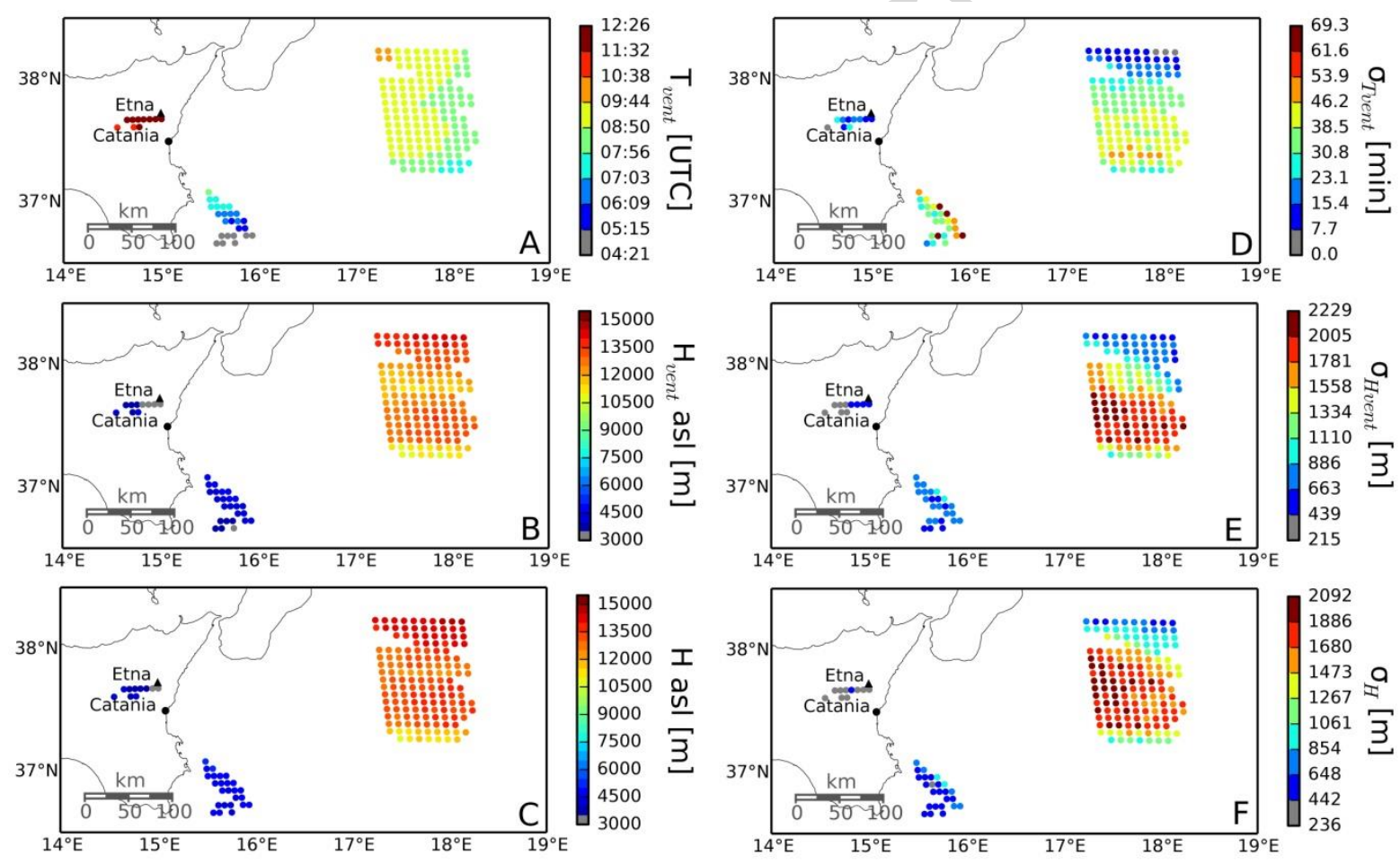

Figure 7: (A-D) Plume injection time $\left(T_{\text {vent }}\right)$ and standard deviation $\left(\sigma_{T_{\text {vent }}}\right)$ at the vent for the 18 March 2012 eruption; (B-E) plume injection height $\left(H_{\text {vent }}\right)$ and standard deviation $\left(\sigma_{H_{\text {vent }}}\right)$ for the same event; $(\mathrm{C}-\mathrm{F})$ volcanic cloud height $(H)$ and standard deviation $\left(\sigma_{\mathrm{H}}\right)$ measured at 12:45 UTC on the same day.

Our results show that the bulk of the $\mathrm{SO}_{2}$ injection took place between 7:00 and 10:40 during the morning of 18 March 2012 at heights ranging between 10000 and $15000 \mathrm{~m}$. No significant variations in the vertical distribution of the volcanic cloud height are observed. Before and after this vigorous phase, from 4:20 to 7:00 and from 10:40 to 12:25 respectively, weaker injections at lower 
altitudes (between 3000 and $4000 \mathrm{~m}$ ) are retrieved with the $\mathrm{SO}_{2}$ cloud proximal to Etna. The standard deviations $\sigma_{T_{v e n t}}$ range between 0 and 54 minutes for the plume injected from 07:00 and 10:40, with the majority $\sim 30$ minutes. The uncertainties on plume height (both $\sigma_{H_{v e n t}}$ and $\sigma_{\mathrm{H}}$ ) range between 200 and 2000 $\mathrm{m}$. It is worth to notice that OMI rows anomalies can have partially cut part of the plume emitted during the eruption. However, the results we obtained are coherent with what has been seen by OMI with more than the $50 \%$ of the plume observed.

\subsection{Trajectory analysis and results: the 12 April 2013 eruption}

The third and final test case is the Etna paroxysmal event that occurred on 12 April 2013. The GOME-2 map is used for the detection of the $\mathrm{SO}_{2}$ plume emitted during the eruption (Figure 8A). From Eq. (1) a $C A_{\text {lim }}$ equal to $1.8 \mathrm{DU}$ is chosen when selecting the pixels used in the retrieval procedure. Note that the pixels centred at a longitude coordinate higher than $18^{\circ}$ are not selected since they are off the wind field grid, see Figure 8B.

Each pixel is divided into sub-pixels with sizes of $12 \mathrm{~km}$ in latitude and $10 \mathrm{~km}$ in longitude resulting in a total number of 333 sub-pixels (Figure 8B). 

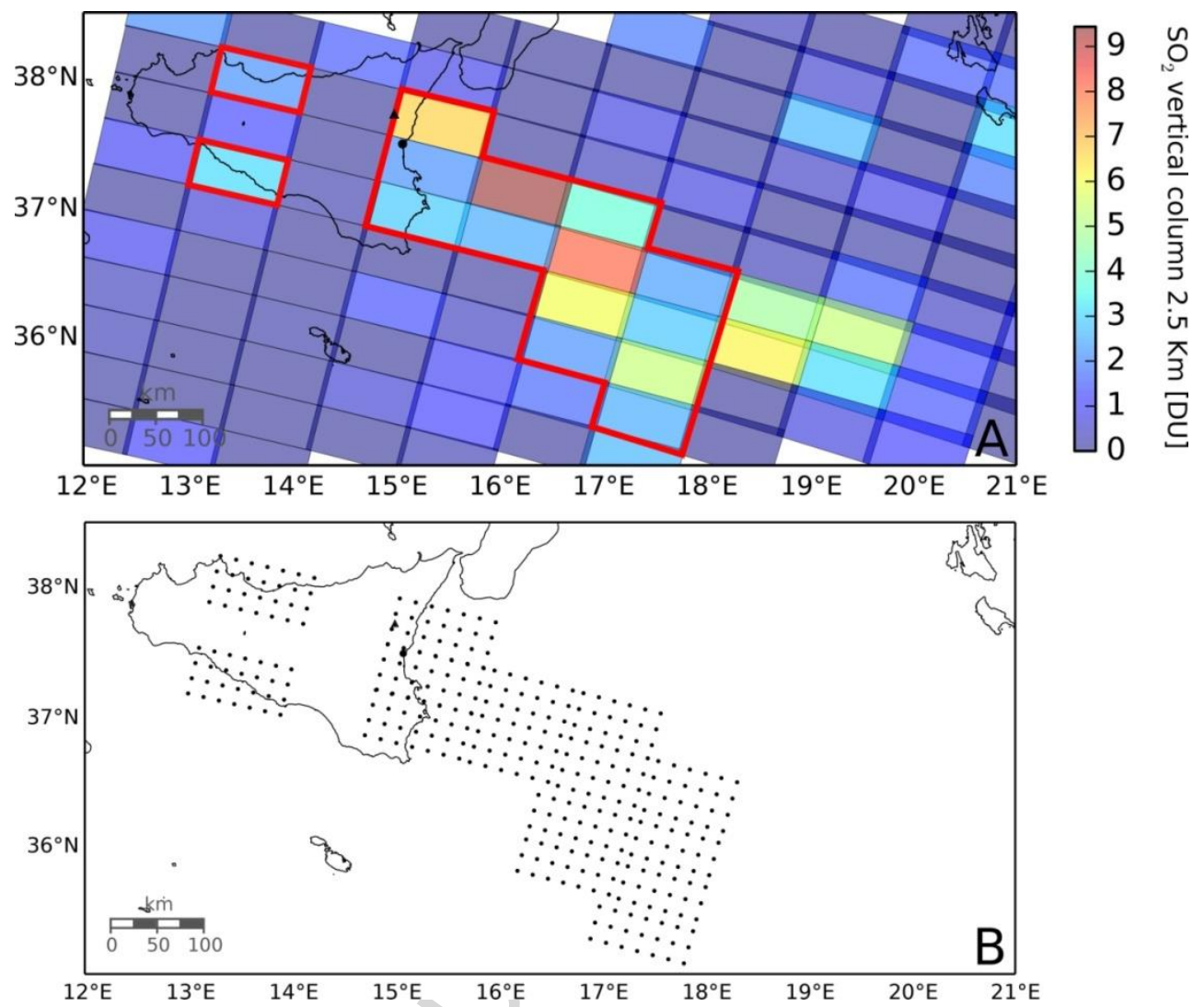

Figure 8: (A) GOME-2 image collected at 08:40 UTC on 12 April 2013 showing the $\mathrm{SO}_{2}$ plume released into the atmosphere during the eruption; pixels with a columnar abundance greater than $1.8 \mathrm{DU}$ are used for the retrieval procedure and are highlighted in red; (B) high resolution grid used to initialise the back-trajectories is composed of sub-pixels sized 10 by $12 \mathrm{~km}$.

We select 20 heights from $3000 \mathrm{~m}$ to $12000 \mathrm{~m}$ every $500 \mathrm{~m}$. This produces 6660 starting points for the back-trajectories and thus a total of 179820 trajectories initialized on 12 April 2013 at 8:40. Using the post-processing procedure previously described, we retrieve mean parameters $\left(T_{\text {vent }}, H_{\text {vent }}, H\right)$ and standard deviations $\left(\sigma_{T_{\text {vent }}}, \sigma_{H_{\text {vent }}}, \sigma_{H}\right)$ for each sub-pixel of the domain. In contrast to the previous examples, for which the injection time interval is restricted to about 2 hours, in this case the $\mathrm{SO}_{2}$ plume captured by GOME-2 is released from 11 April 2013 evening until satellite data collection on 12 April 2013 at 8:40 (see Figure 9A). 
A clockwise decrease in the injection heights from $6500 \mathrm{~m}$ to $3500 \mathrm{~m}$ is observed (see Figure 9B). This is the result of a variation in wind direction with height during the eruption time interval. This trend is reflected also in the volcanic cloud height, with a variation in the mean height from $5000 \mathrm{~m}$ to 3000 m (see Figure 9C).

The majority of sub-pixels produce a $\sigma_{T_{\text {vent }}}$ between 3 and 30 minutes. The presence of an intense wind shear produces a low uncertainty on altitudes both at vent and satellite observation time, with a maximum value for the standard deviations $\left(\sigma_{H_{\text {vent }}}\right.$ and $\left.\sigma_{\mathrm{H}}\right)$ of about $1000 \mathrm{~m}$.
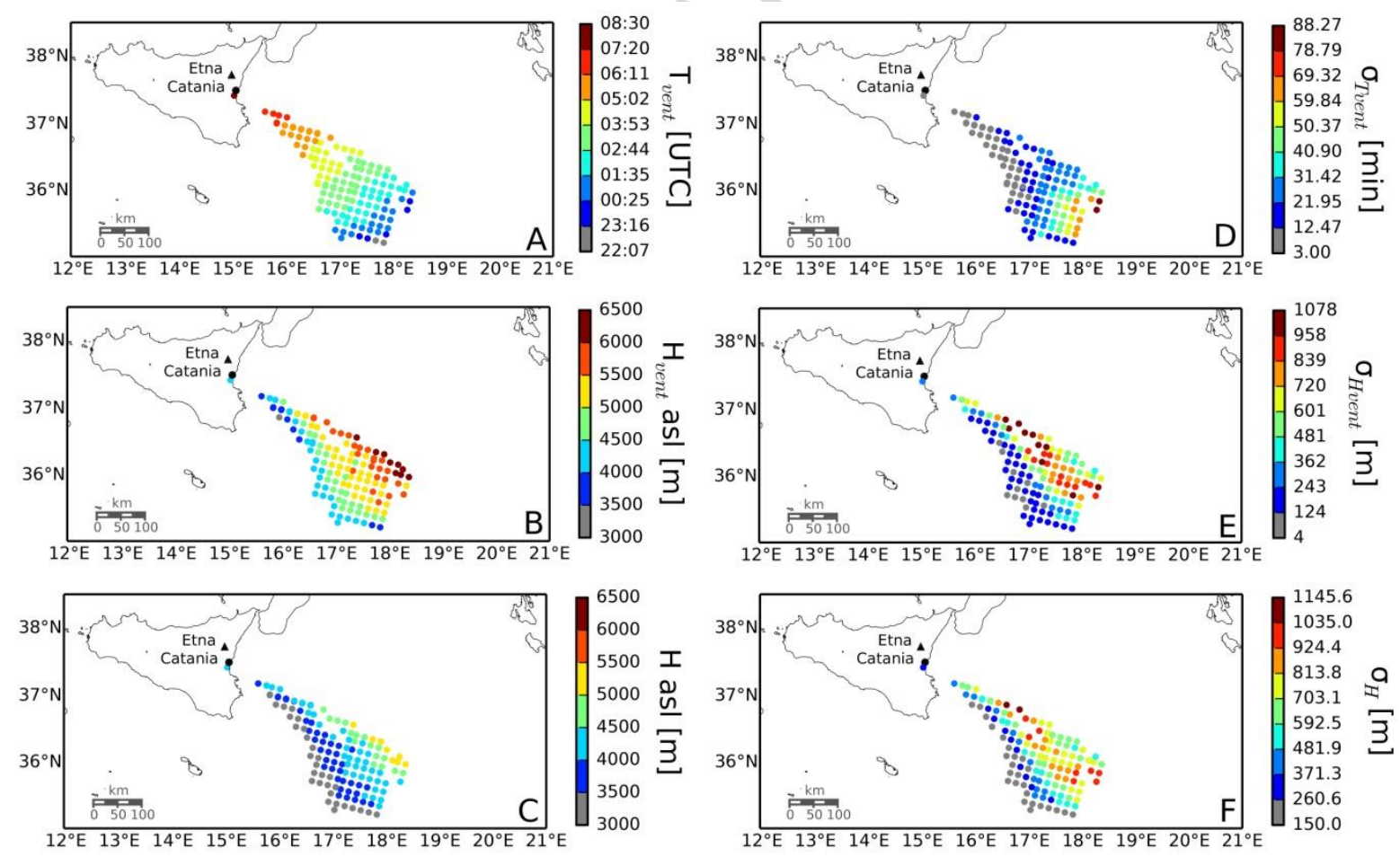

Figure 9: (A) Plume injection time $\left(T_{\text {vent }}\right)$ at the vent for the 12 April 2013 eruption; (B) plume injection height $\left(H_{\text {vent }}\right)$ for the same event; (C) shows the volcanic cloud height $(H)$ measured at 8:40 UTC. 


\section{Intercomparison with satellite and ground-based data}

In this section our retrieved plume parameters (injection time, injection height and volcanic cloud height) are compared with data obtained from independent satellite- and ground-based systems.

The injection time interval is compared with the timing of the eruption observed by INGV's camera networks. For the 12 August 2011 and 18 March 2012 events the timing eruption is the time interval during which lava fountaining has been observed visually (Behncke et al., 2014) and we verify if this time interval is consistent with the one retrieved by the numerical model. As reported in the "Time of eruption [UTC]" section of Table 1, the injection time we retrieved (column named "Back-traj." in the table) fit well with the lava fountain time, showing that the $\mathrm{SO}_{2}$ plumes captured by OMI have been released during the paroxysmal phase of the eruptions. For the 18 March 2012 event this is true considering the pixels with the peak $\mathrm{SO}_{2}$ abundance. For the 12 April 2013 event, the $\mathrm{SO}_{2}$ injection of the plume captured by GOME-2 starts at 22:00 on 11 April 2013 and end at satellite measurement time (12 April 2013 at 8:40 in the morning). This result is consistent with the information coming from ground instruments (visible camera) for the investigated event.

In analysing the retrieved plume heights (injection plume height and volcanic cloud height), we use the mean heights $\left(H_{\text {vent }}\right.$ and $\left.H\right)$ retrieved for the subpixels and we calculate global mean heights at different time intervals for the entire plumes. The "Height at vent position [km]" section of Table 1 shows the comparison between injection heights retrieved by both back-trajectory analysis ("Back-traj." column) and independent satellite- and ground-based techniques. In particular, we use results obtained from the dark pixel procedure applied to SEVIRI data ('Dark Pixel' column) and from the ground-based calibrated VIS camera images ('VIS' column). The dark pixel procedure (Corradini et al., 2010) is based on a comparison between the mean brightness temperature at 11 
$\mu \mathrm{m}$ of the volcanic ash cloud's most opaque pixels, with an atmospheric temperature profile collected near (in time and space) the area of interest. Since it is reasonable to assume that the selected pixels are not completely dark, the temperature of the cloud top is set two degrees lower (Prata and Grant, 2001). The reference temperature is defined using the National Centers for Environmental Prediction (NCEP)/National Center for Atmospheric Research $(\mathrm{NCAR})$ reanalysis profile (resolution $2.5^{\circ} \times 2.5^{\circ}$ ) centred on Etna. This procedure is applied to SEVIRI images collected during the eruptions and presenting dark pixels. The retrieved top plume height at vent location is compared with the global injection height retrieved using our numerical model.

For the 12 August 2011 event, the dark pixel procedure allows us to estimate a mean plume height of $8.1 \mathrm{~km}$ between 9:45 and 10:30. This value is in good agreement with the $8.2 \mathrm{~km}$ global injection height retrieved using the numerical model for the same time interval. The same procedure applied to the 18 March 2012 event lead to a plume height of $12.4 \mathrm{~km}$ which fits well with the global height of $12.9 \mathrm{~km}$ computed by the numerical model in the same time interval (9:00- 10:00).

The SEVIRI data cannot be used for the 12 April 2013 test case because the $\mathrm{SO}_{2}$ column amounts in this case are lower than the SEVIRI's sensitivity limit.

A further comparison for retrieved injection heights is performed using data calculated through image analysis of video collected by the ground-based visible cameras operated by the Osservatorio Etneo (Scollo et al., 2014) (see column "VIS" of Table 1). Images at the maximum of paroxysmal phase are measured using the Camera Calibration Toolbox of Matlab and used to infer the eruptive column height at vent location. The column heights estimated by this method are compared with the retrieved injection height at vent location. For the 12 August 2011 event a column height of $9 \mathrm{~km}$ at 9:23 is consistent with the 
global retrieved quantity of $8.4 \mathrm{~km}$. The global mean injection height of more than $12 \mathrm{~km}$ for the 18 March 2012 event cannot be validated using camera data since the plume is too high to be captured by the uppermost part of the video image. For the 12 April 2013 event, calibrated images collected every hour from 3:00 to 8:00 in the morning give a global mean injection height of $6.1 \mathrm{~km}$, while a slightly lower value equal to $\sim 5 \mathrm{~km}$ is retrieved from the numerical model. Finally, in section "Height at sat. meas. [km]" of Table 1, we compare the retrieved volcanic cloud height with data obtained from the volcanic cloud centre of mass tracking procedure applied to SEVIRI data ('Centre Track' column). The volcanic cloud height retrieval based on ash centre of mass tracking is computed by comparing the wind speed, obtained by following the $\mathrm{SO}_{2}$ centre of mass (i.e. the region with the highest $\mathrm{SO}_{2}$ column abundance) using the series of SEVIRI images, with the wind atmospheric profile of the area of interest. The core hypothesis here is that the speed of the volcanic cloud is advected at the wind speed at the volcanic cloud height, and since the wind profile is known the plume height can be calculated. As an example, Figure 10A shows the time series of the $\mathrm{SO}_{2}$ maps retrieved from SEVIRI data during the 18 March 2012 Etna eruption. Figure 10B shows the estimated distance and directions of the $\mathrm{SO}_{2}$ cloud centre of mass of each image and the corresponding estimated wind speed.

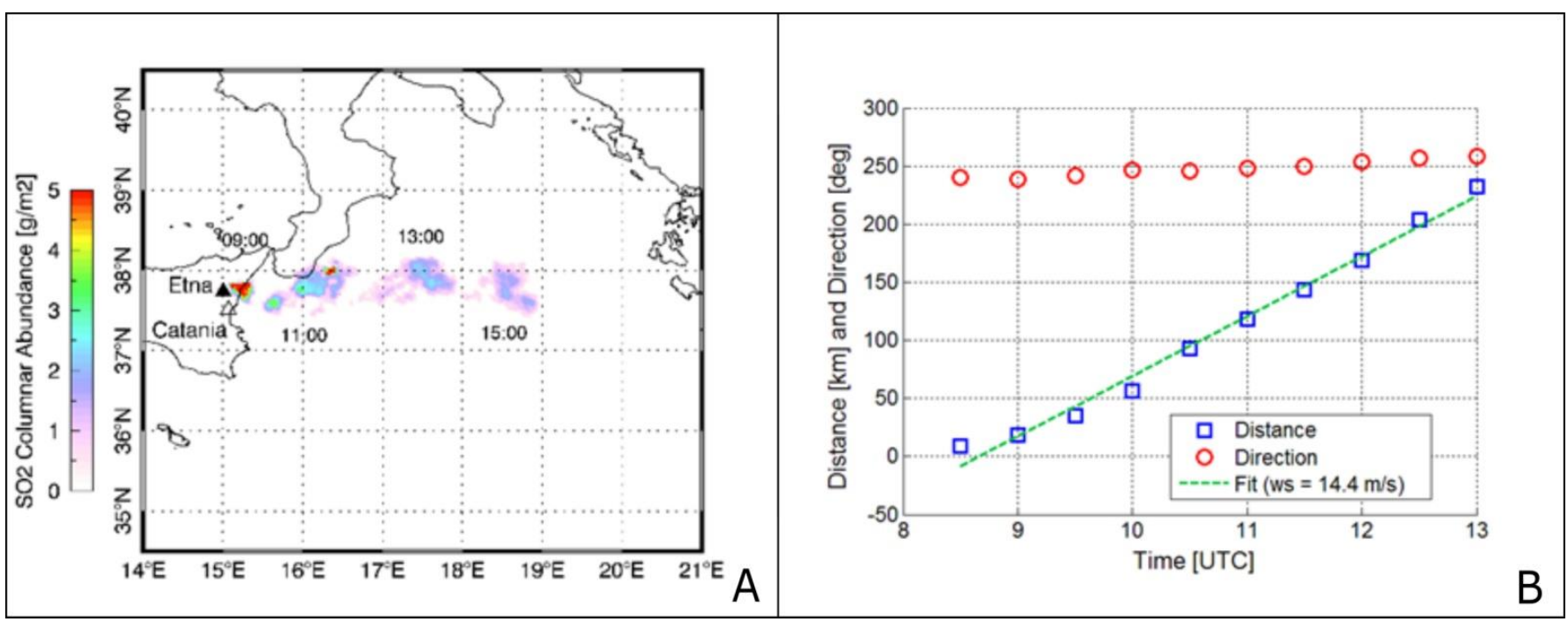


Figure 10: (A) time series of the SEVIRI $\mathrm{SO}_{2}$ maps retrieved during the 18 March 2012 Etna eruption. (B) distance and directions of the $\mathrm{SO}_{2}$ cloud centre of mass and corresponding wind speed.

The volcanic cloud centre of mass procedures produces volcanic heights of 8.5 and $13.0 \mathrm{~km}$ for the 12 August 2011 and 18 March 2012 test cases respectively. These values are in good agreement with the 7.8 and $13.1 \mathrm{~km}$ retrieved from the numerical model for the two test cases.

\begin{tabular}{|c|c|c|c|c|c|c|c|c|}
\hline \multirow[t]{2}{*}{ Date } & \multicolumn{2}{|c|}{$\begin{array}{l}\text { Time of eruption } \\
\text { [UTC] }\end{array}$} & \multicolumn{4}{|c|}{ Height at vent position [km] } & \multicolumn{2}{|c|}{$\begin{array}{c}\text { Height at sat. meas. } \\
\qquad[\mathrm{km}]\end{array}$} \\
\hline & Back-traj. & $\begin{array}{l}\text { Ground } \\
\text { Instr. }\end{array}$ & Time & Back-traj. & Dark Pixel & VIS & Back-traj. & $\begin{array}{l}\text { Centre } \\
\text { track. }\end{array}$ \\
\hline \multirow[t]{3}{*}{ 12-Aug-11 } & $8: 00-10: 30$ & $8: 30-10: 30$ & $8: 00-9: 00$ & $6.4+/-0.4$ & & & \multirow[t]{3}{*}{$7.8+/-1.0$} & \multirow[t]{3}{*}{8.5} \\
\hline & & & $9: 00-9: 45$ & $8.4+/-0.5$ & & $>9[9: 23]$ & & \\
\hline & & & $9: 45-10: 30$ & $8.2+/-0.4$ & $8.1+/-0.3$ & & & \\
\hline \multirow[t]{2}{*}{ 18-Mar-12 } & \multirow[t]{2}{*}{$7: 45-9: 50$} & $8: 00-9: 45$ & $7: 45-9: 00$ & $12.3+/-1.4$ & & & \multirow[t]{2}{*}{$13.1+/-1.2$} & \multirow[t]{2}{*}{13} \\
\hline & & & 9:00-10:00 & $12.9+/-0.8$ & $12.4+/-1.4$ & $>9[9: 16]$ & & \\
\hline 12-Apr-13 & $22: 00-8: 40$ & 22:00-8:00 & $3: 00-8: 40$ & $5+/-0.6$ & & $6.1+/-0.3$ & $4+/-0.5$ & \\
\hline
\end{tabular}

Table 1: Intercomparison between the outcomes of the numerical procedure and estimations made through independent satellite and ground-based analysis. The "Time of eruption [UTC]" section shows the injection time interval retrieved by the numerical model ("Backtraj." column) compared with the eruption time as observed by Ground Instruments ("Ground Instr.” column). In comparing plume altitudes, mean values for the entire plume are calculated using the outcomes of the numerical procedure and they are presented in columns named 'Back-traj'. The "Height at vent position [km] asl" section collects the injection heights numerically calculated at different time intervals during the eruptions. These values are compared with the ones coming both from the dark pixels procedure applied to SEVIRI 
data ("Dark Pixel" column) and from the calibrated visible images collected at vent location ("VIS" column). In the "Height at sat. meas. [km]" section, the volcanic cloud height as retrieved by the numerical model is compared with results coming from the centre mass tracking procedure applied to SEVIRI data, (“Centre track.” column).

\section{Comparison between volcanic tremor and injection height time-series}

The results of the back-trajectory model show a wide range in injection heights during the investigated eruptions. Indeed, while they are all classified as paroxysmal events, they show different injection heights ranging from $3500 \mathrm{~m}$ for the 12 April 2013 eruption to $15000 \mathrm{~m}$ for the 18 March 2012. This variability reflects different eruptive styles and mechanisms within a shallow volcanic feeding system and conduit, and may also, to a lesser degree, reflect external factors influencing the rising of eruptive column, such as the wind field or the temperature profile at volcanic vent location. Using the volcanic tremor signal recorded during the events as a proxy for volcanic activity we can investigate if a link exists between the retrieved $\mathrm{SO}_{2}$ injection heights and the tremor intensity, and therefore volcanic explosivity.

Volcanic tremor is a type of seismicity occurring near active volcanoes before, during and after eruptions (Zobin et al., 2003; Di Grazia et al., 2009). Tremor is characterised by a highly variable duration (from a few minutes to days, or even months) and low frequency range $(1-9 \mathrm{~Hz})$. Several studies have examined the links between tremor and $\mathrm{SO}_{2}$ fluxes (McNutt, 1994). As an example, Nadeau et al., (2011) uses high temporal resolution UV cameras to retrieve $\mathrm{SO}_{2}$ emission rate at Fuego volcano, Guatemala, and shows how degassing rate and tremor amplitude share as common source the inhibition of gas loss from magma as a result of rheological stiffening in the upper conduit of that volcano. Palma, et al. 
(2008) shows a correlation between seismicity and visual observations at Villarrica volcano, Chile, indicating that the seismic tremor is mostly caused by the explosive outgassing activity.

On Etna, a case study by Leonardi et al., (2000) shows a strong correlation between the amplitude of volcanic tremor and $\mathrm{SO}_{2}$ fluxes during the period 1987-1995 and suggests a common physical origin between tremor and $\mathrm{SO}_{2}$ emissions linked to magma dynamics. Zuccarello et al., (2013) shows an anomalous degassing episode well-correlated with an increase in volcanic tremor and in the almost complete absence of eruptive activity from December 2005 to January 2006 at Etna. Finally, Bonaccorso et al., (2011) discusses the mechanism behind the 10 April 2011 paroxysmal episode and displays the strong association between $\mathrm{SO}_{2}$ fluxes and volcanic tremor at Etna. Here, we examine correlations between tremor amplitude time-series and retrieved $\mathrm{SO}_{2}$ injection height time-series at volcanic vent for the three investigated test cases. Alparone et al., (2003) shows a qualitative linear relationship between the maximum amplitude of the tremor signal and the eruptive column height of the early 2000 Etna eruptive cycle. According to the classification reported in Alparone et al., (2003) for Etna's tremor signal, the three investigated eruptions are catalogued as Bell-shaped (12 August 2011 and 18 March 2012 eruptions) and Ramp-shaped (12 April 2013 event). The Bell-shape pattern is characterized by a gradual increase and decrease in the tremor amplitude, whereas the Rampshape presents a slow gradual increase, followed by a sudden decrease. Furthermore, three different phases of the eruptive event can be related to the changing amplitude of the tremor during a volcanic eruption. A first resumption phase, during which both the explosive activity and tremor increase, followed by a paroxysmal phase, which represents the peak of the activity with lava fountaining and the creation of a sustained eruptive column, and a final 
conclusive phase, during which the tremor drops and just Strombolian explosions persist.

We combine together the injection plume heights $\left(H_{\text {vent }}\right)$ and time $\left(T_{\text {vent }}\right)$ retrieved using the back-trajectory model and we create an injection height time-series as shown in Figure 11A. Considering time intervals of 15 minutes, we calculate mean, maximum and minimum values for the injection heights at each time interval (see caption of Figure 11A-B-C) . 

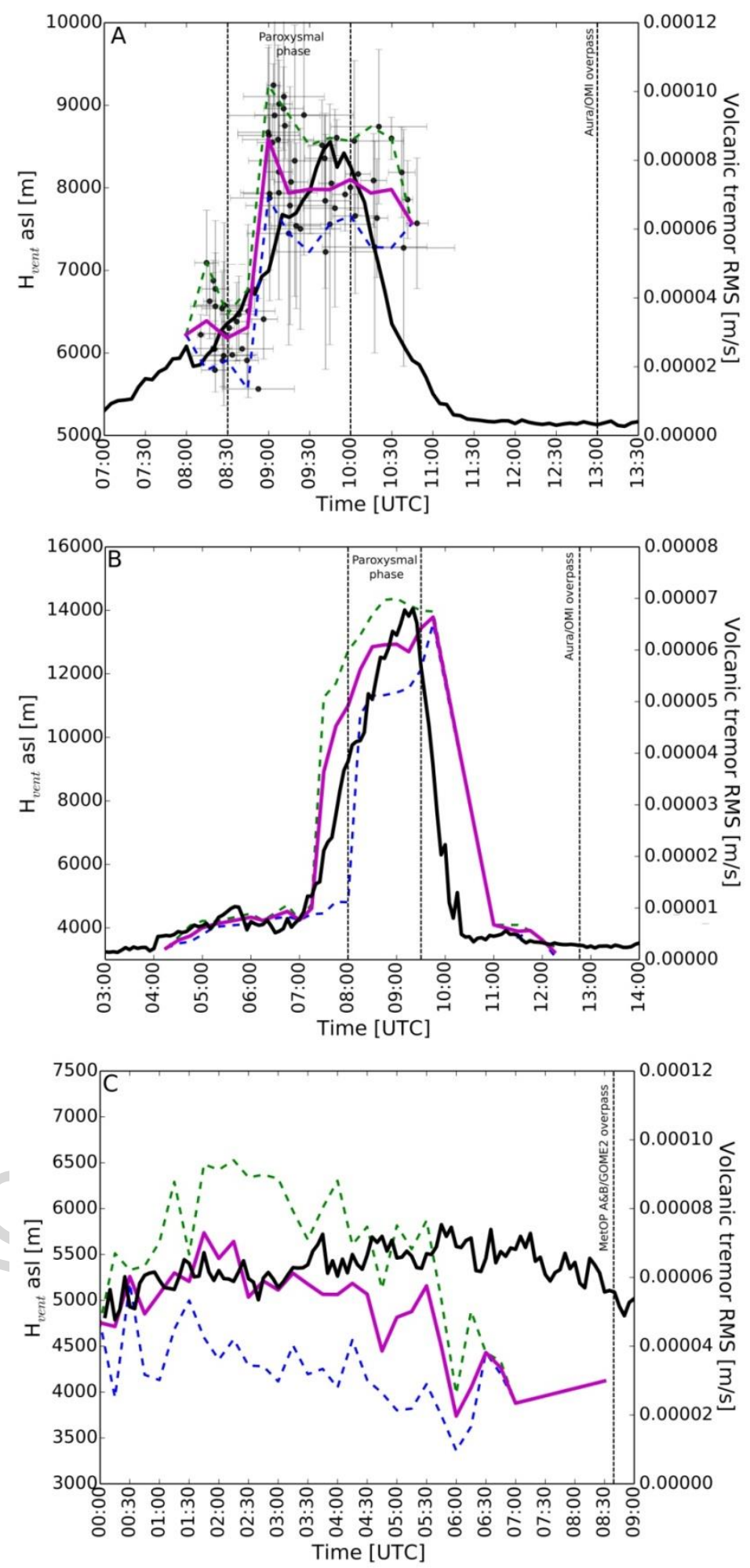

Figure 11: A: Retrieved injection height time-series (black dots with error bars) for the 12 August 2011 eruption. Each dot represents the mean height $\left(H_{\text {vent }}\right)$ and time $\left(T_{\text {vent }}\right)$ at which the $\mathrm{SO}_{2}$ contained in the sub-pixels has been injected into the atmosphere above the volcanic vent position. The weighted standard 
deviations $\left(\sigma_{T_{\text {vent }}}\right.$ and $\left.\sigma_{H_{\text {vent }}}\right)$ are also reported both on the time and on the height axes. The mean injection height time-series is built computing the mean value of the mean altitudes within time intervals of 15 minutes (magenta lines). The maximum and the minimum values within each time bin are also computed. These values allow to constrain the top and the bottom of the plume during the injection into the atmosphere (green and blue dotted lines respectively). In panel $\mathrm{B}$ and $\mathrm{C}$ only the mean altitudes (magenta lines) are plotted for the 18 March 2012 and 12 April 2013 events in order to avoid confusion due to the high number of black dots. Also for these test cases, the blue and the green lines help to constrain the top and the bottom of the plume at vent location. A positive correlation between tremor (continuous black lines) and injection height is observed for the three events.

As observed by INGV-Osseryatorio Etneo, the paroxysmal phase for the 12 August 2011 and 18 March 2012 eruptions matches well with the time interval during which the tremor reaches its peak intensity.

The tremor vs. height pattern for the 12 August 2011 eruption reveals that the bulk of the $\mathrm{SO}_{2}$ captured by OMI has been injected into the atmosphere mostly during the paroxysmal phase of the eruption. For the 18 March 2012 eruption, the $\mathrm{SO}_{2}$ injected during the paroxysmal phase is the one contained in the pixels with the highest values of $\mathrm{SO}_{2}$ columnar abundance. Low altitude injections before and after the paroxysmal phase are associated with pixels presenting a columnar abundance slightly above the background level. For both the test cases there is the evidence of a peak in the $\mathrm{SO}_{2}$ emissions during the paroxysmal phase of the eruption.

In the 12 August 2011 event (see Figure 11A, magenta line) the increasing of the injection heights from $\sim 6500 \mathrm{~m}$ to $\sim 8500 \mathrm{~m}$ is well-correlated with an increase in tremor amplitude from $\sim 3 * 10^{-5} \mathrm{~ms}^{-1}$ to $\sim 8^{*} 10^{-5} \mathrm{~ms}^{-1}$. Similarly, for 
the 18 March 2012 event (see Figure 11B, magenta line), the variation of the injection height from $\sim 4000 \mathrm{~m}$ to $\sim 14000 \mathrm{~m}$ is reflected with an increase in tremor amplitude from $\sim 1 * 10^{-5} \mathrm{~ms}^{-1}$ to $\sim 7 * 10^{-5} \mathrm{~ms}^{-1}$. The injection height time-series for the 12 April 2013 event (see Figure 11C, magenta line) reflects a different trend from the previous test cases, but appears again to be well correlated to the ramp shape tremor signal recorded during the eruption. In this case a constant mean injection height of $\sim 5000 \mathrm{~m}$ is associated with a tremor amplitude of $\sim 6.5^{*} 10^{-5} \mathrm{~ms}^{-1}$.

From this analysis, we find that a wide range of injection height is reached for similar values of tremor intensity. In particular, a tremor intensity of $\sim 6.5 * 10^{-5}$ $\mathrm{ms}^{-1}$ is associated with heights varying from $\sim 5000 \mathrm{~m}$ (12 April 2013) to $13000 \mathrm{~m}$ (18 March 2012). Thus, the relationship between tremor amplitude and injection height appears to be complex.

The non-linear relationship between tremor and plume height could be due to the effects of both eruptive parameters and external atmospheric factors. Vent geometry and mass flow rate need to be considered as well as the role of wind and temperature profile at vent location (Bursik, 2001; Woodhouse et al., 2013).

Detailed examination of the possible mechanisms which might produce such behaviour lies outside the scope of this work, but we do highlight that this observation is an excellent example of the new scientific frontiers that can be opened by performing analysis of satellite $\mathrm{SO}_{2}$ data with a view to understanding volcanic processes.

\section{Conclusions}

In the present paper we use satellite images of $\mathrm{SO}_{2}$ plumes emitted from Etna volcano as input data for a numerical procedure which allows the retrieval of volcanic cloud height, injection plume height and injection plume time. This procedure has been developed with the aim of filling a perceived gap between 
the satellite retrieval of $\mathrm{SO}_{2}$ abundance in the atmosphere and the study of volcanic eruption processes. In particular, we focus our attention on the heights at which the plume is located both at satellite measurement time and during the injection into the atmosphere at vent position, retrieving also the injection time interval.

We found that, despite their often narrow spatial extension, $\mathrm{SO}_{2}$ plumes emitted from Etna exhibit an extremely variable vertical distribution. The retrieved injection heights range from $3500 \mathrm{~m}$ (12 April 2013) to $15000 \mathrm{~m}$ (18 March 2012). The injection time interval also varies from about 2 hours (12 August 2011 and 18 March 2012) to more than 10 (12 April 2013). Moreover, considerable variations in plume height can be found during each test case. We highlight that the results of the back-trajectory model strongly reflect the characteristics of the wind field used in the simulation. In case of uniform wind profile in both direction and intensity, uncertainties on the results are due to the wide range of heights initializing trajectories that pass near the volcanic vent position.

A good correlation between volcanic tremor and injection height time-series is found for the three case studies. In this sense, injection height reflects the intensity of the eruption. However, quantified examination of the relationship between column height and volcanic tremor demonstrates that each case has a different relationship. While the local wind field could influence this relationship, it appears that in these cases the physical eruption mechanism played a key role in controlling the relationship between tremor amplitude and column height.

The procedure we developed can help the development of new strategies in the calculation of $\mathrm{SO}_{2}$ fluxes at vent position. The knowledge of the plume height is 
in fact an essential information in determining the $\mathrm{SO}_{2}$ abundance into the atmosphere and secondly calculated $\mathrm{SO}_{2}$ fluxes.

Finally, since $\mathrm{SO}_{2}$ plume are often used as proxy for volcanic ash, our simple and fast procedure can help in assessing the volcanic cloud height for volcanic hazard mitigation. The procedure we developed requires just one satellite image in order to be performed. This is of particular value for operational real time retrieval of plume heights and age in case of eruptions as soon as the first satellite image has been collected.

\section{Acknowledgements}

The research leading to these results has received funding from the European Research Council under the European Union's Seventh Framework Programme (FP/2007-2013)/ERC Grant Agreement no. 279802, project $283 \mathrm{CO}_{2}$ Volc. This work has been also supported by the project MEDiterranean SUpersite Volcanoes 280 (MED-SUV) WP 3.3.3 (European Community). The authors would like to thank the two anonymous Reviewers for the useful comments on the manuscript and the Italian Civil Protection for the meteorological data used in the paper. 


\section{References}

Alparone, S., Andronico, D., Lodato, L., \& Sgroi, T., 2003. Relationship between tremor and volcanic activity during the Southeast Crater eruption on Mount Etna in early 2000. Journal of Geophysical Research: Solid Earth, 108 (B5), doi: 10.1029/2002JB001866.

Aminou, D. M., 2002. MSG's SEVIRI instrument. ESA Bulletin (0376-4265) (111), 15-17.

Behncke, B., Branca, S., Corsaro, R. A., De Beni, E., Miraglia, L., \& Proietti, C., 2014. The 2011-2012 summit activity of Mount Etna: Birth, growth and products of the new SE crater. Journal of volcanology and geothermal research, 270, 10-21, doi: 10.1016/j.jvolgeores.2013.11.012.

Bekki, S., 1995. Oxidation of volcanic $\mathrm{SO}_{2}$ : a sink for stratospheric $\mathrm{OH}$ and $\mathrm{H}_{2} \mathrm{O}$. Geophysical Research Letters, 22 (8), 913-916, doi: 10.1029/95GL00534.

Blumstein D, Chalon G, Carlier T, Buil C, Hebert P, Maciaszek T, et al., 2004. IASI instrument: technical overview and measured performances. Proc SPIE 2004;5543:196, doi:10.1117/12.560907.

Bluth, G. J., Doiron, S. D., Schnetzler, C. C., Krueger, A. J., \& Walter, L. S., 1992. Global tracking of the $\mathrm{SO}_{2}$ clouds from the June, 1991 Mount Pinatubo eruptions. Geophysical Research Letters , 19 (2), 151-154, doi:10.1029/91GL02792.

Boichu, M., Menut, L., Khvorostyanov, D., Clarisse, L., Clerbaux, C., Turquety, S., et al., 2013. Inverting for volcanic $\mathrm{SO}_{2}$ flux at high temporal resolution using 
spaceborne plume imagery and chemistry-transport modelling: the 2010 Eyjafjallajökull eruption case-study. Atmospheric Chemistry and Physics, 13 (17), 8569-8584, doi:10.5194/acp-13-8569-2013.

Boichu, M., Clarisse, L., Péré, J. C., Herbin, H., Goloub, P., Thieuleux, F., et al., 2015. Temporal variations of flux and altitude of sulfur dioxide emissions during volcanic eruptions: implications for long-range dispersal of volcanic clouds. Atmospheric Chemistry and Physics Discussions , 15 (4), 5031-5077, doi:10.5194/acp-15-8381-2015.

Bonaccorso, A., Caltabiano, T., Currenti, G., Del Negro, C., Gambino, S., Ganci, G., ... \& Spampinato, S., 2011. Dynamics of a lava fountain revealed by geophysical, geochemical and thermal satellite measurements: The case of the 10 April 2011 Mt Etna eruption. Geophysical Research Letters, 38(24), doi: 10.1029/2011GL049637.

Brenot, H., Theys, N., Clarisse, L., Van Geffen, J., Van Gent, J., Van Roozendael, M., ... \& Valks, P., 2014. Support to Aviation Control Service (SACS): an online service for near real-time satellite monitoring of volcanic plumes. Natural hazards and earth system sciences, 14(5), 1099-1123, doi: 10.5194/nhess-14-1099-2014.

Bursik, M., 2001. Effect of wind on the rise height of volcanic plumes. Geophysical Research Letters, 28(18), 3621-3624, doi: 10.1029/2001GL013393.

Burton, M. R., Prata, F., \& Platt, U., 2015. Volcanological applications of $\mathrm{SO}_{2}$ cameras. Journal of Volcanology and Geothermal Research , 300, 2-6, doi:10.1016/j.jvolgeores.2014.09.008. 
Calvari, S., Salerno, G. G., Spampinato, L., Gouhier, M., La Spina, A., Pecora, E., Harris, A. J. L., Labazuy, P., Biale, E. \& Boschi, E., 2011. An unloading foam model to constrain Etna's 11-13 January 2011 lava fountaining episode. Journal of Geophysical Research: Solid Earth , 116 (B11), doi: 10.1029/2011JB008407.

Cao, C., Xiong, J., Blonski, S., Liu, Q., Uprety, S., Shao, X., ... \& Weng, F., 2013. Suomi NPP VIIRS sensor data record verification, validation, and long-term performance monitoring. Journal of Geophysical Research: Atmospheres,118(20), doi: 10.1002/2013JD020418.

Cape, J. N., Methven, J., \& Hudson, L. E., 2000. The use of trajectory cluster analysis to interpret trace gas measurements at Mace Head, Ireland. Atmospheric Environment , 34 (22), 3651-3663, doi: 10.1016/S13522310(00)00098-4.

Carboni, E., Grainger, R., Walker, J., Dudhia, A., \& Siddans, R., 2012. A new scheme for sulphur dioxide retrieval from IASI measurements: application to the Eyjafjallajökull eruption of April and May 2010. Atmospheric Chemistry and Physics , 12 (23), 11417-11434, doi:10.5194/acp-12-11417-2012.

Carboni, E., Grainger, R. G., Mather, T. A., Pyle, D. M., Thomas, G., Siddans, R., et al., 2015. The vertical distribution of volcanic $\mathrm{SO}_{2}$ plumes measured by IASI. Atmospheric Chemistry and Physics Discussions , 15 (17), doi:10.5194/acp-16-4343-2016.

Carn, S. A., Krotkov, N. A., Yang, K., Hoff, R. M., Prata, A. J., Krueger, A. J., et al., 2007. Extended observations of volcanic $\mathrm{SO}_{2}$ and sulfate aerosol in the 
stratosphere. Atmospheric Chemistry and Physics Discussions , 7 (1), 28572871, doi:10.5194/acpd-7-2857-2007.

Carn, S. A., Krueger, A. J., Arellano, S., Krotkov, N. A., and Yang, K., 2008. Daily Monitoring of Ecuadorian volcanic degassing from space, Journal of Volcanology and Geothermal Research, 176, 141-150, doi: 10.1016/j.jvolgeores.2008.01.029.

Carn, S. A., Krueger, A. J., Krotkov, N. A., Yang, K., \& Evans, K., 2009. Tracking volcanic sulfur dioxide clouds for aviation hazard mitigation. Natural Hazards , 51 (2), 325-343, doi: 10.1007/s11069-008-9228-4.

Carn, S.A., Krotkov, N.A., Yang, K. \& Krueger, A.J., 2013. Measuring global volcanic degassing with the Ozone Monitoring Instrument (OMI). Geological Society, London, Special Publications, , 380 (1), 229-257, doi: $10.1144 / \mathrm{SP} 380.12$

Chahine, M. T., et al., 2006. AIRS: Improving weather forecasting and providing new data on greenhouse gases, Bulletin of the American Meteorological Society, 87(7),911-926, doi:10.1175/BAMS-87-7-911, doi: 10.1175/BAMS-87-7-911.

Clarisse, L., Coheur, P.-F., Theys, N., Hurtmans, D., and Clerbaux, C., 2014. The 2011 Nabro eruption, a SO2 plume height analysis using IASI measurements, Atmospheric Chemistry and Physics, 14, 3095-3111, doi: 10.5194/acp-14-3095-2014.

Corradini, S., Merucci, L., Prata, A. J., \& Piscini, A., 2010. Volcanic ash and $\mathrm{SO}_{2}$ in the 2008 Kasatochi eruption: Retrievals comparison from different IR 
satellite sensors. Journal of Geophysical Research: Atmospheres , 115 (D2), doi: 10.1029/2009JD013634.

Di Grazia, G., Cannata, A., Montalto, P., Patanè, D., Privitera, E., Zuccarello, L. \& Boschi, E., 2009. A multiparameter approach to volcano monitoring based on 4D analyses of seismo-volcanic and acoustic signals: The 2008 Mt. Etna eruption. Geophysical Research Letters , 36 (18), doi:10.1029/2009GL039567.

Draxler, R. R., \& Rolph, G. D., 2003. HYSPLIT (HYbrid Single-Particle Lagrangian Integrated Trajectory) NOAA Air Resources Laboratory. Silver Spring, MD.

Flesch, T. K., Wilson, J. D., \& Yee, E., 1995. Backward-time Lagrangian stochastic dispersion models and their application to estimate gaseous emissions. Journal of Applied Meteorology , 34 (6), 1320-1332, doi: 10.1175/1520-0450(1995)034<1320:BTLSDM>2.0.CO;2

Freiman, M. T., \& Piketh, S. J., 2003. Air transport into and out of the industrial Highveld region of South Africa. Journal of Applied Meteorology , 42 (7), 9941002, doi: http://dx.doi.org/10.1175/15200450(2003)042<0994:ATIAOO>2.0.CO;2

Galle, B., Oppenheimer, C., Geyer, A., McGonigle, A.J.S., Edmonds, M., \& Horrocks, L., 2003. A miniaturised ultraviolet spectrometer for remote sensing of SO2 fluxes: a new tool for volcano surveillance. Journal of Volcanology and Geothermal Research , 119 (1), 241-254, doi: 10.1016/S0377-0273(02)00356-6 
Grousset, F. E., Ginoux, P., Bory, A., \& Biscaye, P. E., 2003. Case study of a Chinese dust plume reaching the French Alps. Geophysical Research Letters, 30 (6), doi: 10.1029/2002GL016833.

Guerrieri, L., Merucci, L., Corradini, S., \& Pugnaghi, S., 2015. Evolution of the 2011 Mt. Etna ash and SO2 lava fountain episodes using SEVIRI data and VPR retrieval approach. Journal of Volcanology and Geothermal Research , 291, 6371, doi: 10.1016/j.jvolgeores.2014.12.016.

Hughes, E. J., Sparling, L. C., Carn, S. A., \& Krueger, A. J., 2012. Using horizontal transport characteristics to infer an emission height time series of volcanic $\mathrm{SO}_{2}$. Journal of Geophysical Research: Atmospheres , 117 (D18), doi: 10.1029/2012JD017957.

Kim, B.G., \& Park, S.U., 2001. Transport and evolution of a winter-time Yellow sand observed in Korea. Atmospheric Environment, 35 (18), 31913201, doi: 10.1016/S1352-2310(00)00469-6.

Leonardi, S., Gresta, S., Mulargia, F. (2000). Searching for a significant correlation between volcanic tremor amplitude and SO2 emissions at Mount Etna volcano, Sicily. Geophysical Journal International , 141 (3), 832-834, doi: 10.1046/j.1365-246x.2000.00114.x.

Levelt, P. F., Van den Oord, G. H., Dobber, M. R., Malkki, A., Visser, H., De Vries, J., et al. (2006). The ozone monitoring instrument. IEEE Transactions on geoscience and remote sensing , 44 (5), 1093-1101, doi:10.1109/TGRS.2006.872333. 
Li, C., Joiner, J., Krotkov, N. A., \& Bhartia, P. K. (2013). A fast and sensitive new satellite SO2 retrieval algorithm based on principal component analysis: Application to the ozone monitoring instrument. Geophysical Research Letters , 40 (23), 6314-6318, doi: 10.1002/2013GL058134.

Liao, L. B., Weiss, S., Mills, S., \& Hauss, B. (2013). Suomi NPP VIIRS day-night band on-orbit performance. Journal of Geophysical Research: Atmospheres, 118(22).

Lin, T.H. (2001). Long-range transport of yellow sand to Taiwan in spring 2000: observed evidence and simulation. Atmospheric Environment , 35 (34), 5873-5882.

McBain, M. C., \& Desjardins, R. L. (2005). The evaluation of a backward Lagrangian stochastic (bLS) model to estimate greenhouse gas emissions from agricultural sources using a synthetic tracer source. Agricultural and forest meteorology , 135 (1), 61-72, doi: 10.1016/j.agrformet.2005.10.003.

McCormick, M. P., Thomason, L. W., Trepte, C. R., \& others. (1995). Atmospheric effects of the Mt Pinatubo eruption. Nature , 373 (6513), 399-404, doi:10.1038/373399a0.

McNutt, S. R., Volcanic tremor from around the world: 1992 update,Acta Vulcanol.,5, 197-200, 1994.

Merucci, L., Burton, M., Corradini, S., \& Salerno, G. G. (2011). Reconstruction of SO2 flux emission chronology from space-based measurements. Journal of Volcanology and Geothermal Research , 206 (3), 80-87, doi: 10.1016/j.jvolgeores.2011.07.002 
Mori, T., \& Burton, M. (2006). The SO2 camera: A simple, fast and cheap method for ground-based imaging of $\mathrm{SO} 2$ in volcanic plumes. Geophysical Research Letters , 33 (24), doi: 10.1029/2006GL027916.

Moxnes, E. D., Kristiansen, N. I., Stohl, A., Clarisse, L., Durant, A., Weber, K., \& Vogel, A. (2014). Separation of ash and sulfur dioxide during the 2011 Grímsvötn eruption. Journal of Geophysical Research: Atmospheres , 119 (12), 7477-7501, doi: 10.1002/2013JD021129.

Munro, R., Eisinger, M., Anderson, C., Callies, J., Corpaccioli, E., Lang, R., et al. (2006). GOME-2 on MetOp. Proc. of The 2006 EUMETSAT Meteorological Satellite Conference, Helsinki, Finland, (p. 12-16).

Nadeau, P. A., Palma, J. L., \& Waite, G. P. (2011). Linking volcanic tremor, degassing, and eruption dynamics via SO2 imaging. Geophysical Research Letters , 38 (1), doi: 10.1029/2010GL045820.

Palma, J. L., Calder, E. S., Basualto, D., Blake, S., \& Rothery, D. A. (2008). Correlations between SO2 flux, seismicity, and outgassing activity at the open vent of Villarrica volcano, Chile. Journal of Geophysical Research: Solid Earth, 113 (B10), doi: http://doi.org/10.1029/2008JB005577.

Patanè, D., Aiuppa, A., Aloisi, M., Behncke, B., Cannata, A., Coltelli, M., ... \& Salerno, G. (2013). Insights into magma and fluid transfer at Mount Etna by a multiparametric approach: a model of the events leading to the 2011 eruptive cycle. Journal of Geophysical Research: Solid Earth , 118 (7), 3519-3539, doi: 10.1002/jgrb.50248. 
Platt, U., and Stutz, J.: Differential Optical Absorption Spectroscopy (DOAS), Principle and Applications, ISBN 3-340-21193-4, Springer Verlag, Heidelberg, 2008.

Prata, A. J. and Grant, I. F. (2001), Retrieval of microphysical and morphological properties of volcanic ash plumes from satellite data: Application to Mt Ruapehu, New Zealand. Quarterly Journal of the Royal Meteorological Society, 127: 2153-2179, doi: 10.1002/qj.49712757615.

Pugnaghi, S., Guerrieri, L., Corradini, S., Merucci, L., \& Arvani, B. (2013). A new simplified approach for simultaneous retrieval of SO2 and ash content of tropospheric volcanic clouds: an application to the Mt Etna volcano. Atmospheric Measurement Techniques, 6 (5), 1315-1327 , doi:10.5194/amt-61315-2013.

Rix, M., P. Valks, N. Hao, D. Loyola, H. Schlager, H. Huntrieser, J. Flemming, U. Koehler, U. Schumann, and A. Inness (2012), Volcanic SO2, BrO and plume height estimations using GOME-2 satellite measurements during the eruption of Eyjafjallajökull in May 2010, Journal of Geophysical Research: Atmospheres, 117, D00U19, doi:10.1029/2011JD016718.

Robock, A. (2000). Volcanic eruptions and climate. Reviews of Geophysics , 38 (2), 191-219.

Salerno, G. G., Burton, M. R., Oppenheimer, C., Caltabiano, T., Randazzo, D., Bruno, N., et al. (2009). Three-years of SO2 flux measurements of Mt. Etna using an automated UV scanner array: Comparison with conventional traverses and uncertainties in flux retrieval. Journal of Volcanology and Geothermal Research , 183 (1), 76-83, doi: 10.1016/j.jvolgeores.2009.02.013. 
Salomonson, V. V., Barnes, W., Xiong, J., Kempler, S., \& Masuoka, E. (2002). An overview of the Earth Observing System MODIS instrument and associated data systems performance. Proc. IEEE Int. Geosci. Remote Sens. Symp., pp. 1174-1176.

Scollo, S., Prestifilippo, M., Pecora, E., Corradini, S., Merucci, L., Spata, G., et al. (2014). Eruption column height estimation of the 2011-2013 Etna lava fountains. Annals of Geophysics , doi: 10.4401/ag-6396.

Sears, T. M., Thomas, G. E., Carboni, E., A Smith, A. J., \& Grainger, R. G. (2013). $\mathrm{SO}_{2}$ as a possible proxy for volcanic ash in aviation hazard avoidance. Journal of Geophysical Research: Atmospheres , 118 (11), 5698-5709, doi: 10.1002/jgrd.50505.

Sellitto, P., Sarra, A. d., Corradini, S., Boichu, M., Herbin, H., Dubuisson, P., et al. (2015). Synergistic use of Lagrangian dispersion modelling, satellite and surface remote sensing measurements for the investigation of volcanic plumes: the Mount Etna eruption of 25--27 October 2013. Atmospheric Chemistry and Physics Discussions , 15 (21), 31335-31383, doi:10.5194/acp-16-6841-2016.

Sigurdsson, H., Houghton, B., McNutt, S., Rymer, H., \& Stix, J. (2015). The encyclopedia of volcanoes. Elsevier.

Song, Y., Miao, W., Liu, B., Dai, W., \& Cai, X. (2008). Identifying anthropogenic and natural influences on extreme pollution of respirable suspended particulates in Beijing using backward trajectory analysis. Journal of hazardous materials , 154 (1), 459-468, doi: 10.1016/j.jhazmat.2007.10.064. 
Strow, L. L., Motteler, H., Tobin, D., Revercomb, H., Hannon, S., Buijs, H., ... \& Glumb, R. (2013). Spectral calibration and validation of the Cross-track Infrared Sounder on the Suomi NPP satellite. Journal of Geophysical Research: Atmospheres, 118(22), doi: 10.1002/2013JD020480.

Tan, H. (2004). ASTER: Advanced Spaceborne Thermal Emission and Reflection Radiometer. Recuperado de http://asterweb. jpl. nasa. gov/swir-alert. asp.

Theys, N., Campion, R., Clarisse, L., van Gent, J., Dils, B., Corradini, S., et al. (2013). Volcanic SO2 fluxes derived from satellite data: a survey using OMI, GOME-2, IASI and MODIS. Atmospheric Chemistry and Physics (ACP), doi:10.5194/acp-13-5945-2013.

Thomas, H. E., \& Prata, A. J. (2011). Sulphur dioxide as a volcanic ash proxy during the April--May 2010 eruption of Eyjafjallajökull Volcano, Iceland. Atmospheric Chemistry and Physics, 11 (14), 6871-6880, doi:10.5194/acp-116871-2011

Williams-Jones G, Stix J, Nadeau PA (2008) Using the COSPEC in the field. In: Williams-Jones G, Stix J, Hickson C (eds) The COSPEC Cookbook: Making $\mathrm{SO}_{2}$ Gas Measurements at Active Volcanoes. IAVCEI Methods in Volcanol, 1, pp. 63-119, <http://www.iavcei.org/>

Woodhouse, M. J., Hogg, A. J., Phillips, J. C., \& Sparks, R. S. J. (2013). Interaction between volcanic plumes and wind during the 2010 Eyjafjallajökull eruption, Iceland. Journal of Geophysical Research: Solid Earth, 118(1), 92109, doi: 10.1029/2012JB009592. 
Yang, K., Krotkov, N. A., Krueger, A. J., Carn, S. A., Bhartia, P. K., \& Levelt, P. F. (2007). Retrieval of large volcanic SO2 columns from the Aura Ozone Monitoring Instrument: Comparison and limitations. Journal of Geophysical Research: Atmospheres , 112 (D24), doi:10.1029/2007JD008825.

Yang, K., X. Liu, P. K. Bhartia, N. A. Krotkov, S. A. Carn, E. J. Hughes, A. J. Krueger, R. J. D. Spurr, and S. G. Trahan (2010), Direct retrieval of sulfur dioxide amount and altitude from spaceborne hyperspectral UV measurements: Theory and application, Journal of Geophysical Research: Atmospheres, 115, D00L09, doi:10.1029/2010JD013982.

Young, S. R., Francis, P. W., Barclay, J., Casadevall, T. J., Gardner, C. A., Darroux, B., et al. (1998). Monitoring SO2 emission at the Soufriere Hills volcano: implications for changes in eruptive conditions. Geophysical Research Letters , 25 (19), 3681-3684, doi: 10.1029/98GL01406.

Zhu, L., Huang, X., Shi, H., Cai, X., \& Song, Y. (2011). Transport pathways and potential sources of PM 10 in Beijing. Atmospheric Environment , 45 (3), 594-604, doi: 10.1029/2004GL019732.

Zobin, V. M. (2003). Introduction to volcanic seismology. Elsevier.

Zuccarello, L., Burton, M. R., Saccorotti, G., Bean, C. J., \& Patané, D. (2013). The coupling between very long period seismic events, volcanic tremor, and degassing rates at Mount Etna volcano. Journal of Geophysical Research: Solid Earth , 118 (9), 4910-4921, doi: 10.1002/jgrb.5 


\section{Highlights}

- A semi-automated numerical procedure based on a back-trajectory approach has been developed for retrieving age and height of volcanic $\mathrm{SO}_{2}$ plumes as captured by satellite instruments.

- $\mathrm{OMI}$ and GOME-2 satellite maps have been used in order to detect $\mathrm{SO}_{2}$ plumes emitted during the Etna eruptions that occurred on 12 August 2011, 18 March 2012 and 12 April 2013.

- $\mathrm{SO}_{2}$ plume height at satellite measurement time and injection height time-series have been retrieved for the investigated test-cases.

- Numerical outcomes have been compared with independent satellite and groundbased estimations.

- Retrieved $\mathrm{SO}_{2}$ injection height-time series have been compared with volcanic seismic tremor signal. 